\title{
Genome sequence and spore germination- associated transcriptome analysis of Corynespora cassiicola from cucumber
}

\author{
Shigang Gao ${ }^{1,2+}$, Rong Zeng ${ }^{1,2+}$, Lihui X $u^{1,2}$, Zhiwei Song ${ }^{1,2}$, Ping Gao ${ }^{1,2}$ and Fuming Dai ${ }^{1,2^{*}}$ (D)
}

\begin{abstract}
Background: Corynespora cassiicola, as a necrotrophic phytopathogenic ascomycetous fungus, can infect hundreds of species of plants and rarely causes human diseases. This pathogen infects cucumber species and causes cucumber target spot, which has recently caused large cucumber yield losses in China. Genome sequence and spore germination-associated transcriptome analysis will contribute to the understanding of the molecular mechanism of pathogenicity and spore germination of C. cassiicola.
\end{abstract}

Results: First, we reported the draft genome sequences of the cucumber-sampled C. cassiicola isolate HGCC with high virulence. Although conspecific, HGCC exhibited distinct genome sequence differences from a rubber treesampled isolate (CCP) and a human-sampled isolate (UM591). The proportion of secreted proteins was $7.2 \%$ in HGCC. A total of 28.9\% (4232) of HGCC genes, 29.5\% (4298) of CCP genes and 28.6\% (4214) of UM591 genes were highly homologous to experimentally proven virulence-associated genes, respectively, which were not significantly different $(P=0.866)$ from the average $(29.7 \%)$ of 10 other phytopathogenic fungi. Thousands of putative virulenceassociated genes in various pathways or families were identified in C. cassiicola. Second, a global view of the transcriptome of C. cassiicola spores during germination was evaluated using RNA sequencing (RNA-Seq). A total of 3288 differentially expressed genes (DEGs) were identified. The majority of KEGG-annotated DEGs were involved in metabolism, genetic information processing, cellular processes, the organismal system, human diseases and environmental information processing.

Conclusions: These results facilitate the exploration of the molecular pathogenic mechanism of $C$. cassiicola in cucumbers and the understanding of molecular and cellular processes during spore germination.

Keywords: Corynespora cassiicola, Cucumber, Genome sequence, Virulence-associated gene, Spore germination, RNA-Seq

\footnotetext{
* Correspondence: fumingdai@163.com

†Shigang Gao and Rong Zeng contributed equally to this work.

'Shanghai Runzhuang Agricultural Technology Co., Ltd, Shanghai 201415, China

${ }^{2}$ Shanghai Engineering Research Centre of Low-carbon Agriculture, Institute of Eco-Environment and Plant Protection, Shanghai Academy of Agricultural Sciences, Shanghai 201403, China
}

(C) The Author(s). 2020 Open Access This article is licensed under a Creative Commons Attribution 4.0 International License, which permits use, sharing, adaptation, distribution and reproduction in any medium or format, as long as you give appropriate credit to the original author(s) and the source, provide a link to the Creative Commons licence, and indicate if changes were made. The images or other third party material in this article are included in the article's Creative Commons. licence, unless indicated otherwise in a credit line to the material. If material is not included in the article's Creative Commons licence and your intended use is not permitted by statutory regulation or exceeds the permitted use, you will need to obtain permission directly from the copyright holder. To view a copy of this licence, visit http://creativecommons.org/licenses/by/4.0/ The Creative Commons Public Domain Dedication waiver (http://creativecommons.org/publicdomain/zero/1.0/) applies to the data made available in this article, unless otherwise stated in a credit line to the data. 


\section{Background}

Cucumber target spot caused by C. cassiicola (BerK \& Curt) Wei has recently caused tremendous cucumber yield losses in China [1]. More importantly, C. cassiicola, as a necrotrophic parasitic fungus, can infect more than 500 plant species, including tomato, eggplant, tobacco, rubber, cotton, soybean and balsam pear, in addition to cucumber and cause plant spot diseases [2], which have transitioned from minor to major diseases in the last half century. Additionally, C. cassiicola is an opportunistic pathogen in humans and causes fungal keratitis under suitable conditions [3] and subcutaneous phaeohyphomycosis [4]. Therefore, the pathogenic mechanism of $C$. cassiicola against plants should be well studied to effectively control diseases caused by this pathogen.

For the past few years, research on the pathogenic mechanism of $C$. cassiicola has mainly focused on biological characteristics, pathogenicity differentiation, cloning of virulence-associated genes, etc. It was reported that C. cassiicola sampled from cucumber could grow at 10$35^{\circ} \mathrm{C}$, and its optimum growth temperature was approximately $30^{\circ} \mathrm{C}$ [5]. C. cassiicola spores germinated from one end or both ends at $25-30{ }^{\circ} \mathrm{C}$ with $>90 \%$ relative humidity, and the germination rate in drops of water was the highest. C. cassiicola was able to invade cucumber leaves primarily through direct contact or via stomata [6]. C. cassiicola showed pathogenic and genetic variation among isolates sampled in different host plants, proving that the intraspecific strains of $C$. cassiicola showed high host specialization [2, 7]. Sixty-four C. cassiicola isolates from perilla, cucumber, tomato, aubergine and sweet pepper in Japan were divided into seven pathogenicity groups (PG1PG7) [8]. Cassiicolin, a small secreted glycoprotein, is an important effector of $C$. cassiicola, and contains six different cassiicolin isoforms, Cas1, Cas2, Cas3, Cas4, Cas5 and Cas6, in different C. cassiicola isolates sampled from various hosts and geographical origins [9-11]. The aggressive abilities of isolates were related to the type of isoform, and the isolates carrying the Cas1 gene were the most aggressive to rubber trees. Additionally, some isolates with no Cas gene also generated moderate symptoms on rubber tree leaves, showing that uncharacterized effectors existed in C. cassiicola [10].

Similar to other filamentous fungal pathogens, C. cassiicola requires multiple pathogenic factors, such as cutinase, cell wall-degrading enzymes [12] and cytomembrane- and cell inclusion-degrading enzymes, in addition to the toxin (cassiicolin) to successfully invade host plants and cause disease, which are transported or regulated by multiple pathways of virulence-associated genes, including mitogenactivated protein kinase (MAPK), $\mathrm{Ca}^{2+}$ and cAMP signal pathways etc. [13]. To date, virulence-associated genes of $C$. cassiicola have rarely been cloned and functionally characterized except for two MAPK genes CCk1 [14] and CMP1
[15], and the cassiicolin-encoded gene Cas [16, 17], which are far from thoroughly representing the pathogenic mechanism of $C$. cassiicola. Thus, a great number of virulenceassociated genes remain to be identified, cloned and functionally characterized.

The fungal conidium involved in reproduction is the main type of fungal asexual spore, and is the main form of inoculation and infection [18]. Resting conidia undergo germination and form sporeling hyphae or thalli under suitable conditions such as optimal humidity and temperature [19]. During this process, the progressive reduction in conidia hydrophobicity results in conidia swelling with isotropic growth and subsequent polarized growth, which is characterized as germ tube formation [20]. Conidium germination is usually essential for the fungal aggressiveness and colonization, which requires the involvement of a series of genes with different biochemical activities [18, 21, 22]. Therefore, spore germination-associated gene expression analysis will contribute to the understanding of the molecular mechanism of spore germination and pathogenicity, which has not been reported in C. cassiicola thus far.

Genome sequencing is a high throughput means to identify functional genes combined with homologous matches against functional databases or conserved domain searches $[13,23]$. Furthermore, genome sequences accelerate the cloning of genes and their functional characterization, so it is imperative that the genome sequence of $C$. cassiicola be globally analyzed. Although the genome sequencing of two C. cassiicola isolates, CCP from a rubber tree and UM591 from the contact lens of a patient with keratomycosis, was completed [24, 25], it is still difficult to characterize the gene function in cucumber-sampled isolates due to high genetic variation among isolates from different hosts. RNA sequencing (RNA-Seq) is an effective technique for analyzing the expression of many genes and is widely used to identify differentially expressed genes (DEGs) between different treatments. Therefore, we first presented the draft genome sequence of a cucumber-sampled $C$. cassiicola isolate (HGCC) with high virulence to cucumber, and comparatively analyzed its genome with two other $C$. cassiicola isolates (CCP from a rubber tree and UM591 from a human) and other phytopathogenic ascomycete fungi in multiple families or pathways of virulence-associated genes in this study. Second, we studied the relative transcriptional levels of genes during the spore germination of C. cassiicola HGCC using RNA-Seq. These research results provide a great deal of information revealing the molecular mechanism of pathogenicity and spore germination of C. cassiicola.

\section{Results}

\section{HGCC isolate features}

The HGCC isolate with high virulence to cucumber was selected for de novo sequencing of $C$. cassiicola sampled from cucumber. By being subcultured on potato 
A

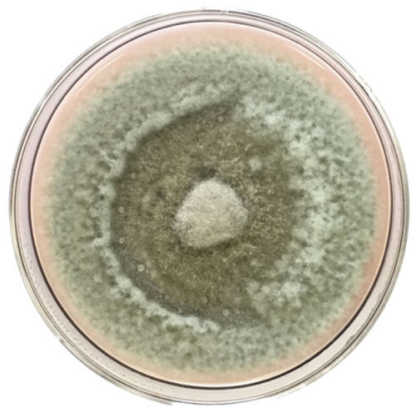

C

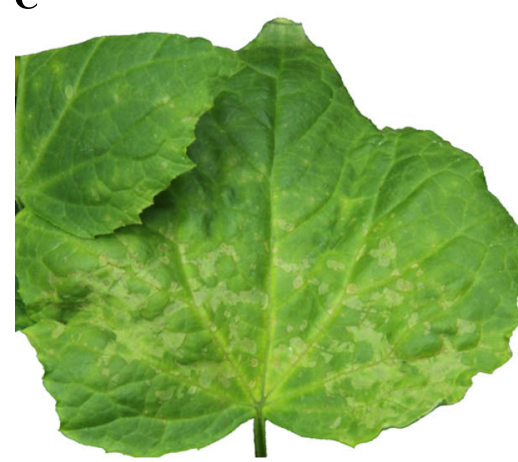

B

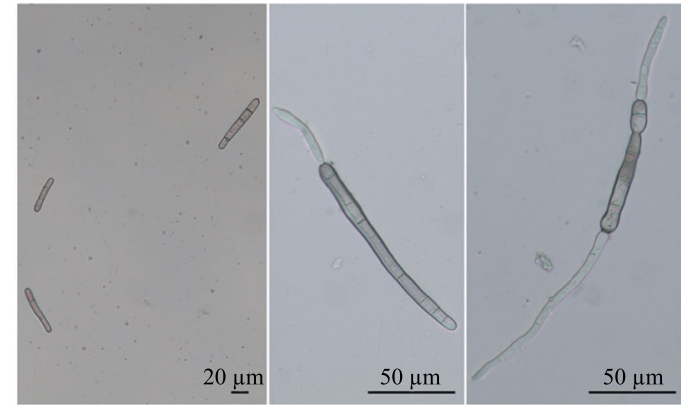

D

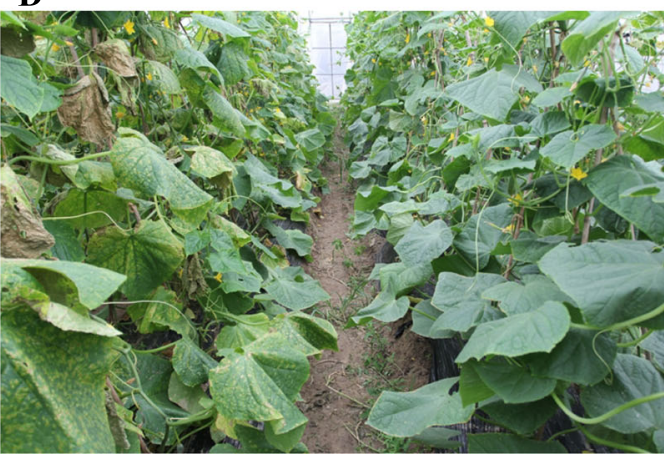

Fig. 1 C. cassiicola isolate HGCC and cucumber target leaf spot symptoms. a HGCC mycelium colony on PDA medium 10 days after subculture at $25^{\circ} \mathrm{C}$ in the dark. $\mathbf{b}$ Optical microscopy observation of HGCC conidia with/without germination in water. c Cucumber target leaf spot symptoms on a susceptible cucumber (Shenqing-1) leaf inoculated by HGCC with $1 \times 10^{5}$ spores ( $60 \mathrm{~h}$ host inoculation). d Cucumber target leaf spot symptoms on the susceptible cucumber cultivar Shenqing-1 (left) and no obvious symptoms on the resistant cucumber cultivar Biyu (right) in a greenhouse in Shanghai

dextrose agar (PDA) plates at $25^{\circ} \mathrm{C}$ in the dark, HGCC produced a layer of fluffy aerial mycelium that was whitish gray when young and dark green when old (Fig. 1a) and easy to peel off. The clubbed conidia were varied in length (from 20 to $120 \mu \mathrm{m}$ ) and shape, had one to nine septa, and germinated at one or both ends in sterile distilled water (Fig. 1b). After artificial inoculation on sensitive and resistant cucumber cultivars, HGCC caused typical symptoms of cucumber target spot disease in the sensitive cultivar Biyu, but it hardly infected the resistant cultivar Shenqing-1 (Fig. 1c and d).

\section{Genome sequencing and general features}

The HGCC genome was de novo sequenced (184x Coverage) using an Illumina HiSeq X 10 system. A total of 54,580,316 high-quality reads were assembled into 1032 scaffolds (N50: $500 \mathrm{~kb}$ ) with a genome size of 42.7 $\mathrm{Mb}$, which was slightly less than that of CCP $(44.8 \mathrm{Mb})$ (JGI: 1019537) and greater than that of UM591 (41.4 Mb) (GenBank: JAQF00000000.1) (Table 1). The HGCC genome encoded 14,631 genes through the coding sequence (CDS) prediction, which was close to the 14,560 of CCP and the 14,744 of UM591 (Table 1). The number of protein-encoding genes in C. cassiicola was significantly different $(P=0.011)$ from the average number $(11$,
664) of 10 other phytopathogenic fungi, including Curvularia lunata, Bipolaris maydis, Cercospora zeaemaydis, Parastagonospora nodorum, Setospaeria turcica, Pyrenophora tritici-repentis, Magnaporthe oryzae, Aspergillus flavus, Fusarium graminearum and Botrytis cinerea (Additional file 1: Table S1). However, the number of secreted proteins in HGCC (1049) was less than that in CCP (1076) and UM591 (1106). The proportions of secreted proteins in the three isolates were $7.2 \%$ for HGCC, 7.4\% for CCP and 7.5\% for UM591, which were

Table 1 Comparison of genome features among the three $C$. cassiicola isolates HGCC, CCP and UM591

\begin{tabular}{llll}
\hline Features & HGCC & CCP & UM591 \\
\hline Assembly size (Mb) & 42.7 & 44.8 & 41.4 \\
Scaffolds & 1032 & 244 & 1941 \\
GC (\%) & 51.78 & 51.89 & 52.47 \\
Repeated sequences (\%) & 0.52 & - & - \\
Protein-coding genes & 14,631 & 14,560 & 14,744 \\
Gene density (genes per Mb) & 343 & 325 & 356 \\
Average CDS length (Bp) & 1575 & 1589 & 1539 \\
Secreted proteins & 1049 & 1076 & 1106 \\
\hline
\end{tabular}


similar to those of the other phytopathogenic ascomycete fungi $(7-10 \%)$ [23].

\section{Interspecific genome-wide phylogeny}

The HGCC genome had a 91.6 and $90.5 \%$ amino acid sequence identity with CCP and UM591, respectively, and a 44.9-57.8\% identity with other phytopathogenic fungi, such as C. lunata (57.4\%), B. maydis (57.1\%), S. turcica (57.0\%), P. nodorum (57.8\%), P. tritici-repentis (56.8\%), C. zeaemaydis (47.0\%), A. flavus (47.5\%), B. cinerea (47.2\%), F. graminearum (46.0\%) and M. oryzae (44.9\%). More than $70 \%$ of HGCC genes had a $>90.0 \%$ amino acid sequence identity with CCP (75.5\%) and UM591 (72.4\%), which was far more than the $55 \%$ between two C. lunata isolates, CX-3 from maize and $\mathrm{m} 118$ from sorghum [23]. A total of 12,986, 13, 057 and 13,253 homologous core genes were screened by reciprocal blast analysis in HGCC, CCP and UM591, of which 2228, 2181 and 2256 were specific to 10 selected pathogenic fungi (Fig. 2a), respectively. Additionally, HGCC, CCP and UM591 had 4.9\% (724), 4.3\% (623) and $4.9 \%$ (722) specific genes compared to each other, of which $0.8 \%$ (118), $0.7 \%(100)$ and $0.9 \%$ (133) were specific to the

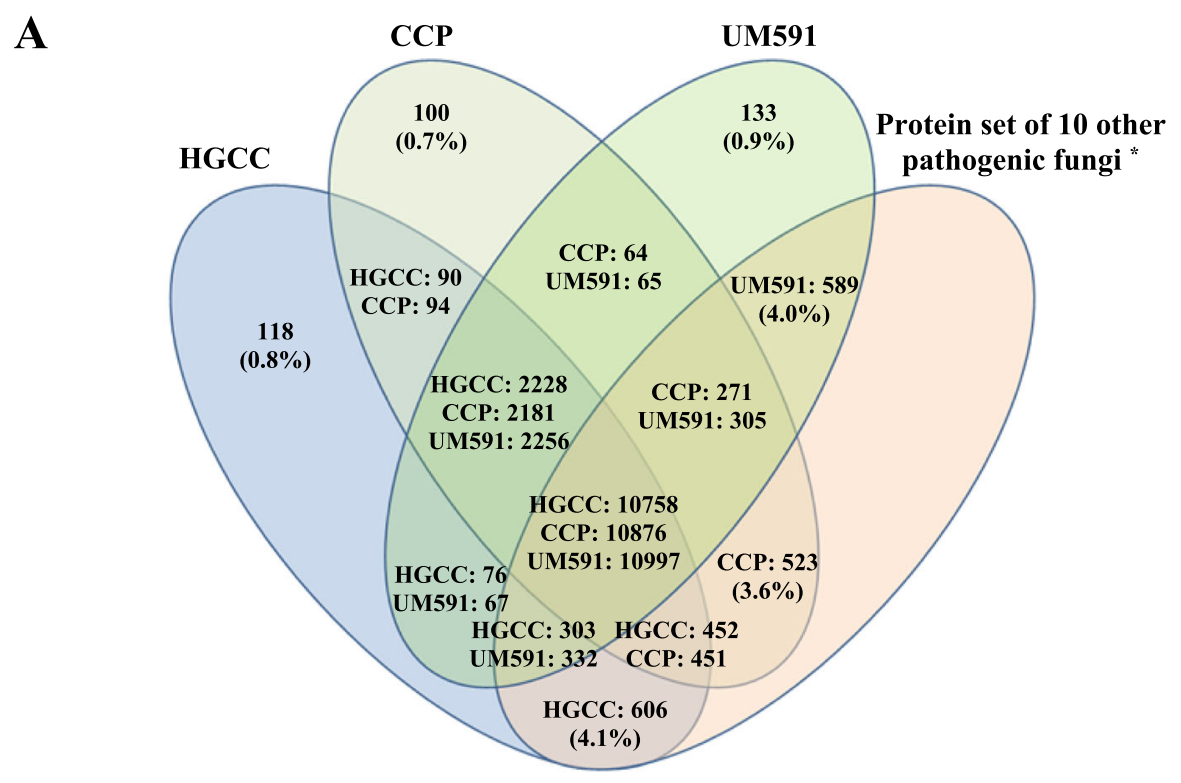

B

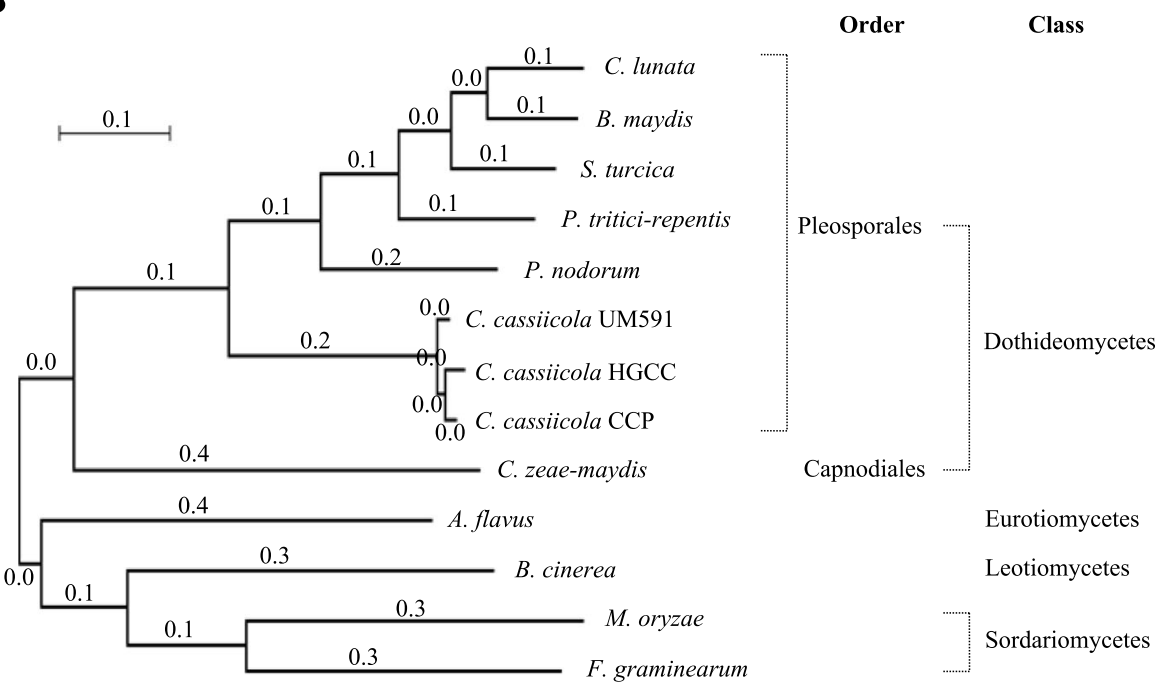

Fig. 2 Comparative genomics and evolutionary analysis of C. cassiicola. a Reciprocal BLAST analysis of the protein sequences among three $C$. cassiicola isolates (HGCC, CCP and UM591) and other phytopathogenic fungi. ${ }^{*}$ Protein set of 10 other phytopathogenic fungi: protein set of 10 other selected phytopathogenic fungi used in evolutionary analysis. b The evolutionary relationship of $C$. cassiicola with selected fungal species is shown by a maximum likelihood phylogenomic tree constructed using MEGA 7.0 software 
10 selected pathogenic fungi, respectively (Fig. 2a and Table 2). It was suggested that the three $C$. cassiicola isolates had distinct differences in their genomes, although HGCC had a high amino acid sequence identity with both $\mathrm{CCP}$ and UM591.

A total of 11,111 gene-encoding proteins were classified into 3892 conserved protein families in HGCC by Pfam matches with profile hidden Markov models, which was close to the 3847 families containing 11,187 proteins in CCP and the 3860 families containing 11,110 proteins in UM591. Glycoside hydrolase (GH), pectate lyase, cutinase and cellulose were important pathogenic factors that were highly abundant in C. cassiicola (Additional file 1: Table S2). There was significant difference in the numbers of transporters $(P=0.043)$, the major facilitator superfamily (MFS) $(P=0.043)$, cytochrome 4450 enzymes (CYPs) $(P=$ $0.011)$, G protein-coupled receptors (GPCRs) $(P=0.028)$,
Pth11-like G protein-coupled receptors $(P=0.011)$, protein kinases $(P=0.011)$, proteases $(P=0.011)$, cysteine proteases $(P=0.017)$, metallo proteases $(P=0.022)$, serine proteases $(P=0.011)$, GHs $(P=0.011)$, pectate lyases $(P=$ $0.011)$, pectinesterases $(P=0.044)$, cellulases $(P=0.045)$, glucosidases $(P=0.010)$ and secondary metabolite backbone genes $(P=0.042)$ between $C$. cassiicola and the 10 other phytopathogenic fungi, and the number of proteins in the each family in the former was more than that in the latter, suggesting that $C$. cassiicola had family expansions in these families. These protein families were expected to play important roles in fungal survival in various adverse environments.

To mine potential virulence-associated genes, BLASTP searches of genomes of the three C. cassiicola and other phytopathogenic fungi were conducted against the pathogen-host interaction (PHI) database at a $E$-value of

Table 2 Genome-wide analysis for C. cassiicola HGCC, CCP and UM591 gene sets

\begin{tabular}{|c|c|c|c|c|c|c|c|c|c|c|}
\hline Characteristics & $\mathrm{HGCC}$ & CCP & UM591 & core $^{\mathbf{a}}$ & $\begin{array}{l}\text { HG-CCP-UM591 } \\
\text { core }^{\mathbf{b}}\end{array}$ & $\begin{array}{l}\text { HG-CCP-UM591 } \\
\text { specific }^{c}\end{array}$ & $\begin{array}{l}\text { HG } \\
\text { specific }^{\mathbf{d}}\end{array}$ & $\begin{array}{l}\text { CCP } \\
\text { specific }^{\text {e }}\end{array}$ & $\begin{array}{l}\text { UM591 } \\
\text { specific }^{\text {f }}\end{array}$ & $\begin{array}{l}\mathrm{HGCC} \\
\mathrm{PHI}\end{array}$ \\
\hline Protein-encoding gene & $\begin{array}{l}14 \\
631\end{array}$ & $\begin{array}{l}14 \\
560\end{array}$ & 14,744 & $\begin{array}{l}10 \\
758\end{array}$ & 12,986 & 2228 & 118 & 100 & 133 & 4232 \\
\hline Secreted protein & 1049 & 1076 & 1106 & 816 & 1003 & 187 & 3 & 1 & 7 & 358 \\
\hline $\mathrm{PHI}$ & 4232 & 4298 & 4214 & 3484 & 4208 & 724 & 3 & 0 & 0 & - \\
\hline Protease & 612 & 625 & 621 & 509 & 614 & 105 & 0 & 0 & 0 & 258 \\
\hline Glycoside hydrolase & 262 & 262 & 265 & 223 & 262 & 39 & 0 & 0 & 0 & 141 \\
\hline Lipase & 21 & 23 & 20 & 17 & 21 & 4 & 0 & 1 & 0 & 9 \\
\hline Glucanase & 30 & 33 & 32 & 29 & 29 & 0 & 0 & 0 & 0 & 24 \\
\hline Glucosidase & 13 & 13 & 16 & 10 & 10 & 0 & 0 & 0 & 0 & 13 \\
\hline Xylanase & 7 & 9 & 9 & 6 & 6 & 0 & 0 & 0 & 0 & 4 \\
\hline Pectate lyase & 34 & 33 & 33 & 28 & 34 & 6 & 0 & 0 & 0 & 30 \\
\hline Cutinase & 8 & 8 & 9 & 7 & 8 & 1 & 0 & 0 & 0 & 5 \\
\hline Cellulase & 14 & 17 & 16 & 14 & 14 & 0 & 0 & 0 & 0 & 5 \\
\hline Pectinesterase & 4 & 4 & 5 & 4 & 4 & 0 & 0 & 0 & 0 & 4 \\
\hline MFS transporter & 238 & 246 & 240 & 196 & 238 & 42 & 0 & 0 & 0 & 230 \\
\hline $\mathrm{ABC}$ transporter & 51 & 50 & 48 & 41 & 51 & 10 & 0 & 0 & 0 & 51 \\
\hline P450 & 218 & 214 & 209 & 177 & 218 & 41 & 0 & 0 & 0 & 198 \\
\hline Protein kinase & 154 & 156 & 151 & 127 & 154 & 27 & 0 & 0 & 0 & 150 \\
\hline Histidine kinase & 11 & 12 & 11 & 9 & 11 & 2 & 0 & 0 & 0 & 11 \\
\hline GPCR & 157 & 159 & 173 & 133 & 157 & 24 & 0 & 0 & 0 & 96 \\
\hline Pth11-like GPCR & 62 & 61 & 57 & 50 & 62 & 12 & 0 & 0 & 0 & 53 \\
\hline CFEM-containing protein & 18 & 19 & 19 & 19 & 20 & 1 & 0 & 0 & 0 & 12 \\
\hline $\begin{array}{l}\text { Fungal specific transcription } \\
\text { factor }\end{array}$ & 202 & 217 & 212 & 162 & 202 & 40 & 0 & 0 & 1 & 187 \\
\hline $\begin{array}{l}\text { Backbone gene for secondary } \\
\text { metabolism }\end{array}$ & 52 & 51 & 49 & 49 & 49 & 0 & 3 & 3 & 0 & 50 \\
\hline
\end{tabular}

a core: C. cassiicola HGCC, CCP and UM591 and 10 other phytopathogenic ascomycetes genes grouped by reciprocal BLAST analysis with a cutoff $E$-value of 1e-5; ${ }^{b}$ HGCC-CCP-UM591 core: HGCC genes present in both CCP and UM591 grouped by reciprocal BLAST analysis with a cutoff $E$-value of $1 \mathrm{e}-5$; ${ }^{\mathrm{C}} \mathrm{HGCC}-\mathrm{CCP}-\mathrm{UM} 591$ specific: HGCC genes present in both CCP and UM591 but specific compared to 10 other fungi grouped by reciprocal BLAST analysis with a cutoff $E$-value of $1 \mathrm{e}-5$; ${ }^{d}$ HG specific: specific genes of HGCC against CCP, UM591, and 10 other fungi; ${ }^{\text {e } C C P}$ specific: specific genes of CCP against HGCC, UM591, and 10 other fungi; ${ }^{f}$ UM591 specific: specific genes of UM591 against HGCC, CCP, and 10 other fungi 
1e-5. A total of $28.9 \%$ (4232) of HGCC genes, $29.5 \%$ (4298) of CCP genes and 28.6\% (4214) of UM591 genes were matched with PHI database, respectively. There was no significant difference $(P=0.866)$ in the percentage of PHIassociated genes between the three $C$. cassiicola and the 10 other phytopathogenic fungi (average: 29.7\%) (Additional file 1: Table S1).

An interspecific phylogenomic tree of C. cassiicola and the 10 other phytopathogenic fungi was constructed based on concatenated amino acid sequences of 2831 orthologous proteins (Fig. 2b). The tree showed that C. cassiicola of the Pleosporales order had genetic affinity with other fungi of the Pleosporales order, followed by C. zeaemaydis of the Capnodiales order of the Dothideomycetes class, A. flavus of the Eurotiomycetes class, B. cinerea of the Leotiomycetes class, and $M$. oryzae and F. graminearum of the Sordariomycetes class. In addition, it was shown in the tree that C. cassiicola speciation had occurred before the speciation of the other Pleosporales fungi, suggesting that $C$. cassiicola speciation had occurred before speciation of the Pleosporales order. These results were similar to the results of David Lopez [24].

\section{Pathogenic signal pathway}

GPCRs transduce external environmental signals by way of heterotrimeric $\mathrm{G}$ proteins into secondary messengers to regulate gene expression and the subsequent cellular response [26]. These proteins are required in plant recognition and pheromone/nutrient sensing of phytopathogenic fungi [27]. Pth11, as one GPCR of Magnaporthe grisea, mediates appressorium differentiation and fungal pathogenicity [28], and its homologues exist in other phytopathogenic fungi. The HGCC genome contained 157 GPCRs, which was close to the 159 in CCP, less than the 173 in UM591. The number of GPCRs in C. cassiicola was significantly different $(P=0.028)$ from the average (113) of the 10 other phytopathogenic fungi (Additional file 1: Table S3). These GPCRs of $C$. cassiicola were classified into 9 classes, including A, B, C, D, E, F, MPR, PTH11 and STM1. The numbers of GPCRs of A (67 in HGCC, 68 in CCP and 87 in UM591), C (7 in HGCC, 8 in CCP and 11 in UM591) and PTH11 (62 in HGCC, 61 in CCP and 57 in UM591) classes in C. cassiicola were significantly different $(P<0.05)$ from the average (50 in A class, 5 in $C$ class and 37 in PTH11 class) of the other phytopathogenic fungi, respectively. More than $80 \%$ of Pth11-like GPCRs were identified as PHI-associated genes in HGCC (53/62), CCP (50/61), UM591 (48/57)), and the 10 other phytopathogenic fungi (average: 32/37), respectively. The G protein alpha subunit is an important component of the heterotrimeric G protein complex [29] and can activate downstream effectors and plays an important role in fungal pathogenicity [30, 31]. In the HGCC genome, three G protein alpha subunits were identified, all of which were
PHI-associated genes and showed high amino acid identities with a G protein beta subunit of Pseudocercospora fijiensis (GenBank: XP_007925889.1, 93\%) and two G protein alpha subunits of Stemphylium lycopersici (GenBank: KNG46771.1, 95\%; GenBank: KNG45504.1, 85\%), respectively.

MAPK, cAMP and $\mathrm{Ca}^{2+}$ signaling are part of major signaling pathways and are associated with virulence in phytopathogenic fungi, which are controlled by a series of protein kinases [13]. Three MAPK pathways of Saccharomyces cerevisiae, FUS3/KSS1, Mpk1 and Hog1, have been well studied and are highly conserved in other fungi [13]. Based on homologous searches of the HGCC genome against known MAPK, cAMP or $\mathrm{Ca}^{2+}$ pathway-associated genes in S. cerevisiae, 48, 12 and 23 screened genes in HGCC were highly homologous with MAPK, cAMP and $\mathrm{Ca}^{2+}$ signal pathway genes of $S$. cerevisiae, respectively (Additional file 1: Tables S4, S5 and S6). A total of 154, 156 and 151 protein kinases were identified in HGCC, CCP and UM591, respectively, which were significantly different $(P=0.011)$ from 116 to 140 in other phytopathogenic fungi (Fig. 3, Additional file 1: Table S7). These protein kinases were classified into 8 classes. There was significant difference $(P<0.05)$ in the numbers of protein kinases in the Other and STE classes between C. cassiicola and the other phytopathogenic fungi, respectively. The STE class (16 kinases for HGCC, 15 for CCP, and 17 for UM591) and MAPK family (4 kinases for HGCC, 3 for both CCP and UM591) in the CMGC class were involved in the MAPK pathway. The PKA family (3 kinases for HGCC, 2 for both CCP and Um591) of the AGC class was involved in the cAMP pathway. The CLK family (1 kinase for HGCC, 3 for CCP, and 2 for UM591) and the RCK family (1 kinase for HGCC, 2 for CCP, and 1 for UM591) of the CMGC class, the CAMK class (20 kinases for HGCC, 18 for CCP, and 20 for UM591), and the PKC family (1 kinase for each of HGCC, CCP and UM591) in the AGC class were related to the $\mathrm{Ca}^{2+}$ pathway. Interestingly, almost all protein kinases were $\mathrm{PHI}$-associated genes in HGCC (150/154), CCP (154/156), UM591 (148/151), and the 10 other phytopathogenic fungi (average: 125/ 129), suggesting that protein kinases played key roles in pathogenic processes mainly mediated by the three pathogenic signal pathways.

Histidine kinase (HK) phosphorelay signaling is usually used by fungi, bacteria, plants and slime molds to sense and adapt to their environment [32]. Fungal HK phosphorelay signaling mediates multiple biological processes, including virulence, differentiation, stress response and the biosynthesis of secondary metabolites [32, 33]. The HK signaling pathway is also known as a two-component signaling pathway containing a sensor $\mathrm{HK}$ and a response regulator (RR). HGCC, CCP and UM591 contained 11, 12 and $11 \mathrm{HKs}$, respectively, which were not significantly 


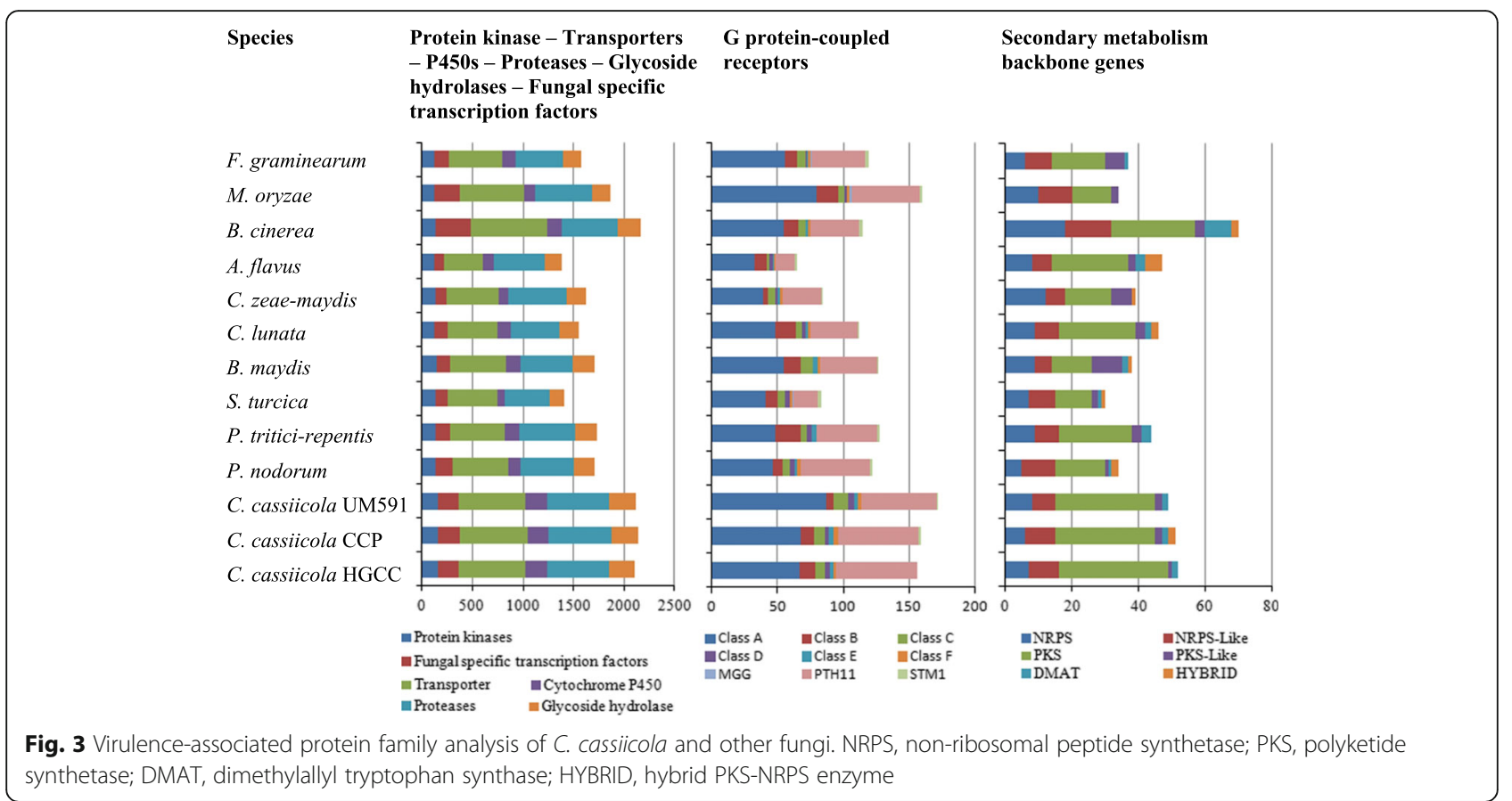

different $(P=0.492)$ from the average (10) of the other phytopathogenic fungi (Additional file 1: Table S7). It is worth noting that all HKs were PHI-associated genes.

\section{Protein families involved in degrading the plant cuticle, cell wall, cytomembrane and cell inclusion}

To successfully invade the host plant, phytopathogenic fungi are expected to produce and secrete multiple extracellular degrading enzymes, such as cutinase for the degradation of the cuticle [34], cell wall-degrading enzymes (pectinase, cellulase and hemicellulase) [35], and cytomembrane- and cell inclusion-degrading enzymes (protease and lipase) [36, 37]. Eight, 8 and 9 cutinases were identified in the HGCC, CCP and UM591 genomes, respectively (Additional file 1: Table S2), which were not significantly different $(P=0.051)$ from the average (11) in the 10 other phytopathogenic fungi. There was significant difference $(P=0.011)$ in the number of pectate lyases, a type of pectinase, between $C$. cassiicola (34 in HGCC, 33 in CCP, and 33 in UM591) and the other phytopathogenic fungi (average: 12). However, pectinesterase, another type of pectinase, was less abundant than pectate lyase in C. cassiicola (4 in HGCC, 4 in CCP, and 5 in UM591) and the other phytopathogenic fungi $(0-5)$. Fourteen, 17 and 16 cellulases were identified in HGCC, CCP and UM591, respectively, which were significantly different $(P=0.045)$ from the average $(12)$ in the other phytopathogenic fungi. The hemicellulase glucanase (30 in HGCC, 33 in CCP, and 32 in UM591), glucosidase (13 in HGCC, 13 in CCP, and 16 in UM591) and xylanase (7 in HGCC, 9 in CCP, and 9 in UM591) were abundant in C. cassiicola, of which only glucosidase showed significant difference $(P=0.010)$ in number between $C$. cassiicola and the other phytopathogenic fungi (average: 9). More than half of cutinases and xylanases and almost all of pectate lyases, pectinesterases, glucanases and glucosidases were PHI-associated genes in these phytopathogenic fungi.

Proteases were very abundant in the $C$. cassiicola genomes (612 in HGCC, 625 in CCP, and 621 in UM591), which were significantly different $(P=0.011)$ from the average value (521) of the other phytopathogenic fungi (Additional file 1: Table S8). More than $40 \%$ of proteases were PHI-associated genes in HGCC (258/612), CCP (261/625), UM591 (254/621), and the 10 other phytopathogenic fungi (average: 226/521), respectively. These proteases were classified into 6 superfamilies, including the serine protease, metallo peptidase, cysteine peptidase, aspartic peptidase, threonine peptidase and glutamic peptidase superfamilies, the first three of which were the largest. The numbers of the serine proteases (355 in HGCC, 364 in CCP and 370 in UM591), metallo peptidases (136 in HGCC, 141 in CCP and 133 in UM591) and cysteine peptidases (74 in HGCC, 73 in both CCP and UM591) in C. cassiicola were significantly different $(P<0.05)$ from the average of the other phytopathogenic fungi (276 serine proteases, 111 metallo peptidases, and 65 cysteine peptidases) (Fig. 3, Additional file 1: Table S8). Aspartic peptidases are virulence factors in both plant and mammalian pathogens due to their ability to cleave a large number of host proteins [38]. C. cassiicola contained 11, 10 and 9 A11 transposon peptidases of the 
aspartic peptidase superfamily in $\mathrm{HGCC}, \mathrm{CCP}$ and UM591, respectively. HGCC, CCP and UM591 contained 21, 23 and 20 lipases, respectively, which were not significantly different $(P=0.864)$ from the average (20) of the other phytopathogenic fungi (Additional file 1: Table S2).

$\mathrm{GH}$ catalyzes the hydrolysis of glycosidic bonds in complex sugars [39], playing a role in fungal pathogenesis. C. cassiicola contained $44 \mathrm{GH}$ families (Additional file 1: Table S9). There were 262 GHs in HGCC, 262 in CCP, and 265 in UM591, which were significantly different $(P=0.011)$ from the average (194) in the other phytopathogenic fungi. Many GH families exhibited gene expansion in C. cassiicola when compared to the other phytopathogenic fungi, including the GH1, GH2, GH3, GH7, GH12, GH20, GH27, GH35, GH43, GH53, GH61, GH72, GH88, GH106 and GH107 families; however, the GH30 and GH 65 families exhibited gene constriction. More than half of GHs were PHI-associated genes in HGCC (141/262), CCP (138/262), UM591 (141/265), and the other phytopathogenic fungi (average: 100/194). Interestingly, almost all GHs of the GH3, GH7, GH10, GH17, GH18, GH20, GH28, GH31, GH61 and GH72 families were PHI-associated genes in C. cassiicola and the 10 other phytopathogenic fungi. It was reported that the GH6, GH7, GH45 and GH61 cellulases and GH10 xlyanases were absent in insect pathogenic fungi but present in phytopathogenic fungi [40]. The GH families of cellulases were abundant in HGCC (69), CCP (70) and UM591 (70), including GH3 (25 in HGCC, 26 in CCP, and 26 in UM591), GH 6 (2 each in HGCC, CCP, and UM591), GH7 (6 each in HGCC, CCP, and UM591), GH45 (2 each in HGCC, CCP and UM591), and GH61 (34 each in HGCC, CCP and UM591) cellulases. The GH16 family of xyloglucosy transferases plays an important role in the digestion of plant cell walls, and was abundant in HGCC (15), CCP (15) and UM591 (16) at values close or equal to the average (15) of the other phytopathogenic fungi.

\section{Protein families for transportation}

C. cassiicola contained a large number of transporters (664 in HGCC, 669 in CCP, and 665 in UM591), which were significantly different $(P=0.043)$ from the average (548) of the other phytopathogenic fungi (Additional file 1: Table S10). More than $70 \%$ of transporters were PHIassociated genes in C. cassiicola HGCC, CCP, UM591 and the other phytopathogenic fungi. The MFS (238 in HGCC, 246 in CCP and 240 in UM591) and ATPbinding cassette $(\mathrm{ABC})$ superfamily (51 in HGCC, 50 in CCP and 48 in UM591) superfamily were the two largest superfamilies of transporters. The former is capable of transporting small solutes in response to chemiosmotic ion gradients, and the latter transports small molecules and macromolecules under ATP hydrolysis [41, 42]. There was significant difference $(P=0.043)$ in the number of MFS transporters between $C$. cassiicola and the other phytopathogenic fungi (average: 160). However, there was no significant difference $(P=0.127)$ in the number of $\mathrm{ABC}$ transporters between $C$. cassiicola and the other phytopathogenic fungi (average: 43). Notably, almost all MFS transporters and all $\mathrm{ABC}$ transporters were $\mathrm{PHI}$-associated genes in these phytopathogenic fungi, showing that MFS and $A B C$ transporters played key roles in fungal pathogenicity.

In phytopathogenic fungi, drug transporters of $\mathrm{ABC}$ and MFS superfamilies can secrete endogenous fungal virulence factors such as toxins and protect pathogens against exogenous plant defense compounds such as phytoalexins [40, 43]. Two drug: $\mathrm{H}^{+}$antiporter (DHA) subfamilies (DHA1 and DHA2), drug transporters of the MFS superfamily, can secrete toxic compounds into the outer environment [44]. The multidrug resistance (MDR) and pleiotropic drug resistance (PDR) subfamilies are drug transporters of the $\mathrm{ABC}$ superfamily that are capable of functioning in antifungal agent resistance [44]. There was almost no difference among the HGCC, CCP and UM591 genomes in the numbers of DHA1 (42, 43 and 44, respectively), DHA2 (5, 7 and 7, respectively), MDR (10, 9 and 9, respectively) and PDR (15, 15 and 14, respectively) (Additional file 1: Table S11), but there was significant difference $(P=0.042)$ in the number of DHA1 transporters between $C$. cassiicola and the other phytopathogenic fungi (average: 32). Interestingly, all drug transporters were PHI-associated genes except for DHA2 (4/5).

\section{Protein families for detoxification}

CYPs are proteins of a superfamily, are ubiquitous in all biological kingdoms, and contain heme as a cofactor and are therefore hemoproteins. Fungal CYPs play key roles in various metabolic processes, such as housekeeping biochemical reactions, detoxification of chemicals and adaptation to adverse surroundings [45]. A large number of CYPs were identified in the C. cassiicola HGCC (218), CCP (214) and UM591 (209) genomes and classified into 112 families; there was significant difference $(P=0.011)$ in the number of CYPs between $C$. cassiicola and the other phytopathogenic fungi (average: 122) (Fig. 3, Additional file 1: Table S12). Interestingly, more than $90 \%$ of CYPs were involved in PHI in HGCC (198/218), CCP (196/214), UM591 (194/209) and the other phytopathogenic fungi (average: 111/122). The CYP65 and CYP505 subfamilies participate in the biosynthesis of mycotoxins; for example, the CYP65 subfamily catalyzes the epoxidation reaction in trichothecene biosynthesis in F. graminearum [46], and both CYP65 and CYP505 are required in fumonisin biosynthesis by Fusarium verticillioides [47, 48], showing that the CYP65 and CYP505 subfamilies 
were probably related to mycotoxin biosynthesis in $C$. cassiicola. CYP65 was the largest subfamily in the CYP superfamily. There was significant difference $(P=0.011)$ in the number of CYP65s between $C$. cassiicola (22 in HGCC, 23 in CCP and 25 in UM591) and the other phytopathogenic fungi (average: 11). Additionally, CYP505 was scarce in C. cassiicola (5 in HGCC, 4 in CCP and 5 in UM591) and the other phytopathogenic fungi (average: 3$)$.

\section{Secondary metabolite backbone genes}

Melanin and mycotoxin are important virulence factors in phytopathogenic fungi [49]. To data, melanin- and mycotoxin-associated genes have not yet been identified in C. cassiicola except for the cassiicolin-coded Cas gene. Secondary metabolite backbone genes are essential for the biosynthesis of melanin and mycotoxin as secondary metabolites. There was significant difference $(P=$ 0.042 ) in the number of backbone genes between $C$. cassiicola (52 in HGCC, 51 in CCP and 49 in UM591) and the other phytopathogenic fungi (average: 42) (Additional file 1: Table S13). Notably, almost all backbone genes (50/52) were $\mathrm{PHI}$-associated genes, showing that they were probably involved in the pathogenic process of these phytopathogenic fungi. The backbone genes of HGCC and UM591 were classified into 5 groups, including nonribosomal peptide synthetase (NRPS), NRPS-like, polyketone synthase (PKS), PKS-like, dimethylallyl tryptophan synthase (DMAT), excluding hybrid PKS-NRPS enzyme (HYBRID), but which existed in CCP. PKS was the largest group in phytopathogenic fungi. The numbers of PKSs in C. cassiicola (33 in HGCC, 30 in CCP, 30 in UM591) were significantly different $(P=0.011)$ from that of the other phytopathogenic fungi (average: 17).

To analyze the relationship between the PKS domain and its function, phylogenetic analysis for the ketoacyl CoA synthase (KS) domain of PKS was performed among C. cassiicola PKSs and role-known PKSs in other pathogenic fungi (Fig. 4). These PKSs were divided into two different clusters based on the phylogenetic analysis. One cluster was reducing PKSs with KS, acyltransferase (AT) and dehydratase $(\mathrm{DH})$ domains at a minimum, which contained 25 C. cassiicola PKSs and 6 known PKSs involved in the biosynthesis of mycotoxins in the other phytopathogenic fungi, such as Aspergillus ochraceus AoLC35-12 for ochratoxin production, Alternaria alternate ACTTS3 for ACT-toxin production, B. maydis PKS1 and PKS2 for Ttoxin production, Gibberella zeae PKS4 for zearalenone production, and Gibberella moniliformis Fum1p for fumonisin production. Two reducing PKSs (g13578 and g7009) were specific to CCP when compared to HGCC. The second cluster contained nonreducing PKSs with KS and AT domains at a minimum and did not include dehydratase $(\mathrm{DH})$, enoyl reductase (ER) and ketoreductase (KR) domains; this cluster contained $10 \mathrm{PKSs}$ of $C$. cassiicola and 9 known PKSs related to melanin biosynthesis in other fungal pathogens such as Aspergillus fumigatus Alb1p, Ceratocystis resinifera PKS1, Colletotrichum lagenarium PKS1, Chaetomium globosum PKS-1, Ascochyta rabie PKS1, B. maydis PKS18, S. turcica StPKS, Bipolaris oryzae PKS1, and $A$. alternata ALM1. It was difficult to identify which reducing PKSs were involved in mycotoxin biosynthesis in C. cassiicola due to the complicated evolutionary relationship for the KS domain of the reducing PKSs in C. cassiicola and known mycotoxin-related PKSs in other fungi. Nevertheless, the nonreducing PKS HGCC_7666 of C. cassiicola had the closest evolutionary relationship with known melanin-associated nonreducing PKSs, suggesting that HGCC_7666 was probably the backbone gene for melanin synthesis in C. cassiicola.

\section{Small, cysteine-rich peptides and effector proteins}

Small cysteine-rich proteins (SCRPs) can be secreted directly into host plant cells to function in host recognition or colonization [50] and the stimulation of the host hypersensitive response (HR) [51]. Some SCRPs, as virulence effectors, facilitate fungal virulence in multiple ways, including host cell signaling perturbation, interference with pathogen recognition by the host and suppression of pathogen-associated molecular pattern (PAMP)-triggered immunity (PTI) [52]. Some SCRPs, such as Avr genes, trigger or suppress effector-triggered immunity (ETI) mediated by a gene-for-gene system in PHI [53]. Fifty-nine SCRPs were identified in HGCC ranging in size from 69 to 150 amino acids, including 1 hydrophobin, 1 ceratoplatanin, 1 CFEM and 3 Avr-encoded proteins (AvrLm47) that were putative effector proteins (Additional file 1: Table S14). Fungal hydrophobins are involved in surface recognition [54], and play a role as effectors in the PHI [55]. Cerato-platanin family proteins could elicit disease resistance responses in the host plant [56].

Lysin motif (LysM)-containing effectors are ubiquitous in phytopathogenic fungi and are secreted out of the cell to suppress the immune response of the host $[57,58]$. Common in the fungal extracellular membrane (CFEM) domain is a fungi-specific domain containing eight cysteines that is found in some proteins with proposed roles in fungal infection and colonization [59, 60]. HGCC contained 6 LysM-containing and 18 CEEM-containing genes that were candidate effectors and were probably involved in the fungal pathogenic process.

\section{Gene expression in spore germination}

To reveal the molecular and cellular processes during spore germination of C. cassiicola, $6 \mathrm{~h}$ - and $12 \mathrm{~h}$-germination times were selected for RNA-Seq based transcriptome analysis. After $12 \mathrm{~h}$ at $25^{\circ} \mathrm{C}$ in sterile $\mathrm{dd}_{2} \mathrm{O}$, the majority of spores germinated at two ends, and only a few 


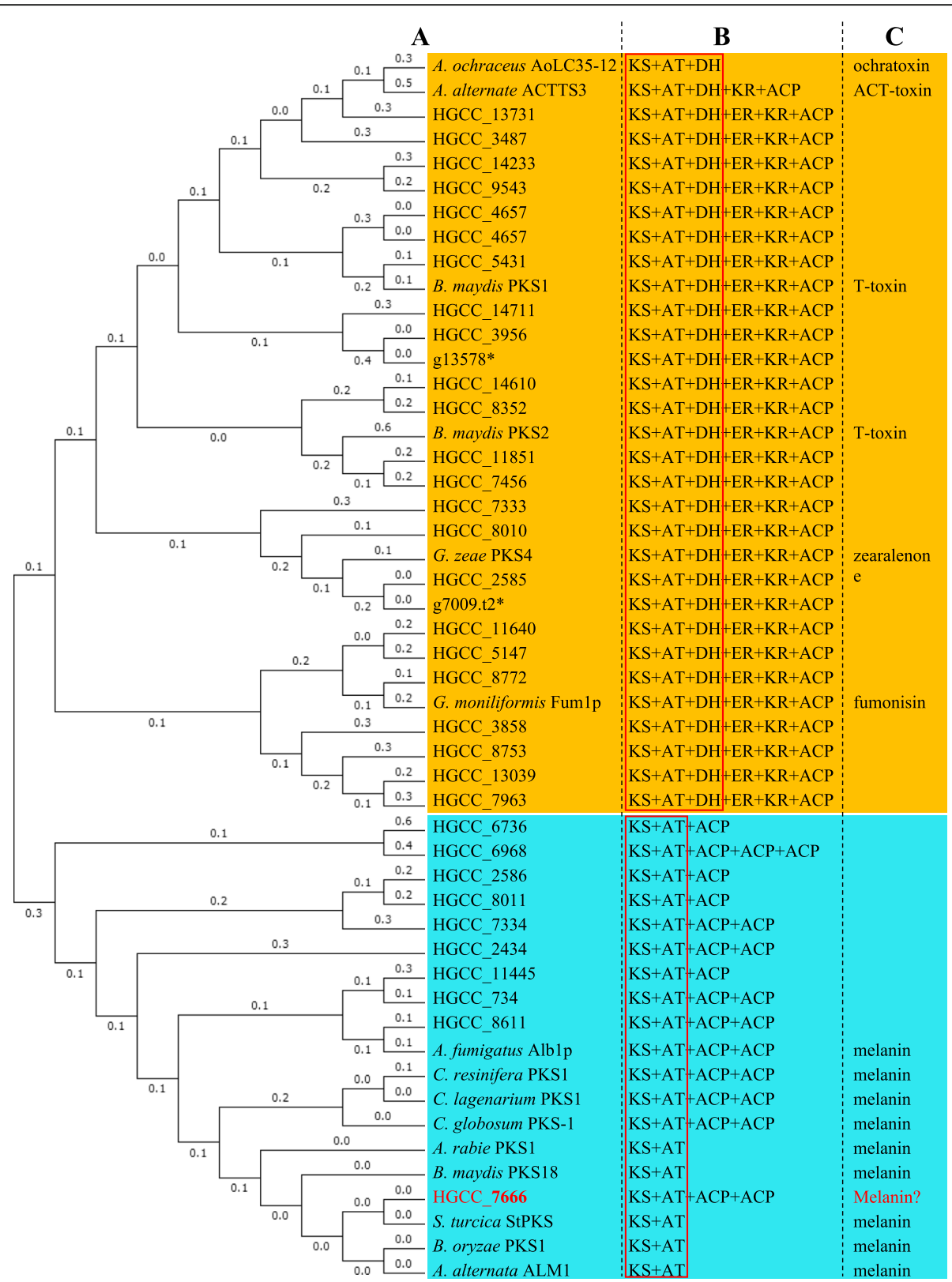

Fig. 4 Phylogenetic and domain analysis of polyketide synthases (PKS) in C. cassiicola HGCC and other fungi. a A maximum likelihood tree of ketoacyl CoA synthase (KS) domain sequences of PKS in selected fungi. b Domain analysis of these PKSs using the SBSPKS database. Domain definitions were as follows: KS, ketoacyl CoA synthase; AT, acyltransferase domain; DH, dehydratase domain; ER, enoyl reductase domain; KR, ketoreductase domain; ACP, acyl carrier protein domain. c Toxins and melanin related to reported PKS in other fungi, the accession No. of which are shown in the "Methods" section. "g13578 and "g7009 are specific in CCP when compared to HGCC

germinated at one end (Fig. 1B). Biological triplicate samples of germinated and ungerminated spores of C. cassiicola were harvested for RNA isolation. RNA-Seq libraries were constructed and sequenced using Illumina HiSeq X ten. Following quality control and adapter trimming, 611, 310,902 bp clean paired reads were obtained from 6 C. cassiicola RNA-Seq libraries. The sequencing yield from individual libraries ranged from $84,671,942$ to $116,800,420$ reads per sample (Table S15 in Additional file 2). Pearson correlation analysis showed that samples of the same treatment were highly correlated with each other in gene expression levels, with the $\mathrm{R}^{2}$ values of $0.885-1$, which were higher than the $\mathrm{R}^{2}$ values of $0.742-0.85$ between samples of different treatments (Fig. S1), suggesting that samples in the same treatment group were repeatable and that the RNA-Seq data were reliable. A total of $66-73 \%$ of $C$. cassiicola filtered reads per library mapped to the gene predictions of C. cassiicola. A total of 3288 genes were 
differentially expressed, of which 1552 and 1736 were upregulated and down-regulated, respectively, during spore germination of $C$. cassiicola with ungerminated spores as the reference (Fig. 5). Specific DEGs are listed in Table S16 in Additional file 2. These DEGs contained hundreds of previously identified functional genes from the genome sequences classified by gene families (Table 3 ).

These DEGs were used for the analysis of gene ontology (GO) and pathway. A total of 2600 DEGs (79.08\%) were annotated by gene ontology (GO). GO term analysis for C. cassiicola revealed an enrichment of cellular process, localization, metabolic process, regulation of biological process and single-organism process, and binding and catalytic activity (Fig. 6). A total of 891 DEGs (34.27\%) were annotated by Kyoto Encyclopaedia of Genes and Genomes (KEGG) pathway analysis, containing 624 up-regulated DEGs and 267 down-regulated DEGs. Gene numbers and IDs for each pathway category are listed in Table S17 in Additional file 2, and the top 20 enriched pathway terms are shown in Fig. 7. The pathway enrichment indicated that the majority of the
KEGG-annotated DEGs were involved in metabolism, genetic information processing, cellular processes, organismal systems, human diseases and environmental information processing.

\section{qRT-PCR validation of selected DEGs}

qRT-PCR assays were conducted to validate the gene expression patterns of 66 DEGs containing 49 upregulated and 17 down-regulated genes. As shown in Fig. 8, qRT-PCR data were correlated with the RNA-Seq data $\left(R^{2}=0.7434\right)$. The expression patterns of 56 DEGs were confirmed by qRT-PCR, and 10 were not (Table S18 in Additional file 2). These results showed a high correlation of RNA-Seq and qRT-PCR results, indicating that the RNA-Seq data were very reliable.

\section{Discussion}

C. cassiicola is a fungal phytopathogen, capable of infecting hundreds of plants and causing leaf spot disease [1]. In this study, we reported the genome sequence and the spore germination-related transcriptome of a cucumber-

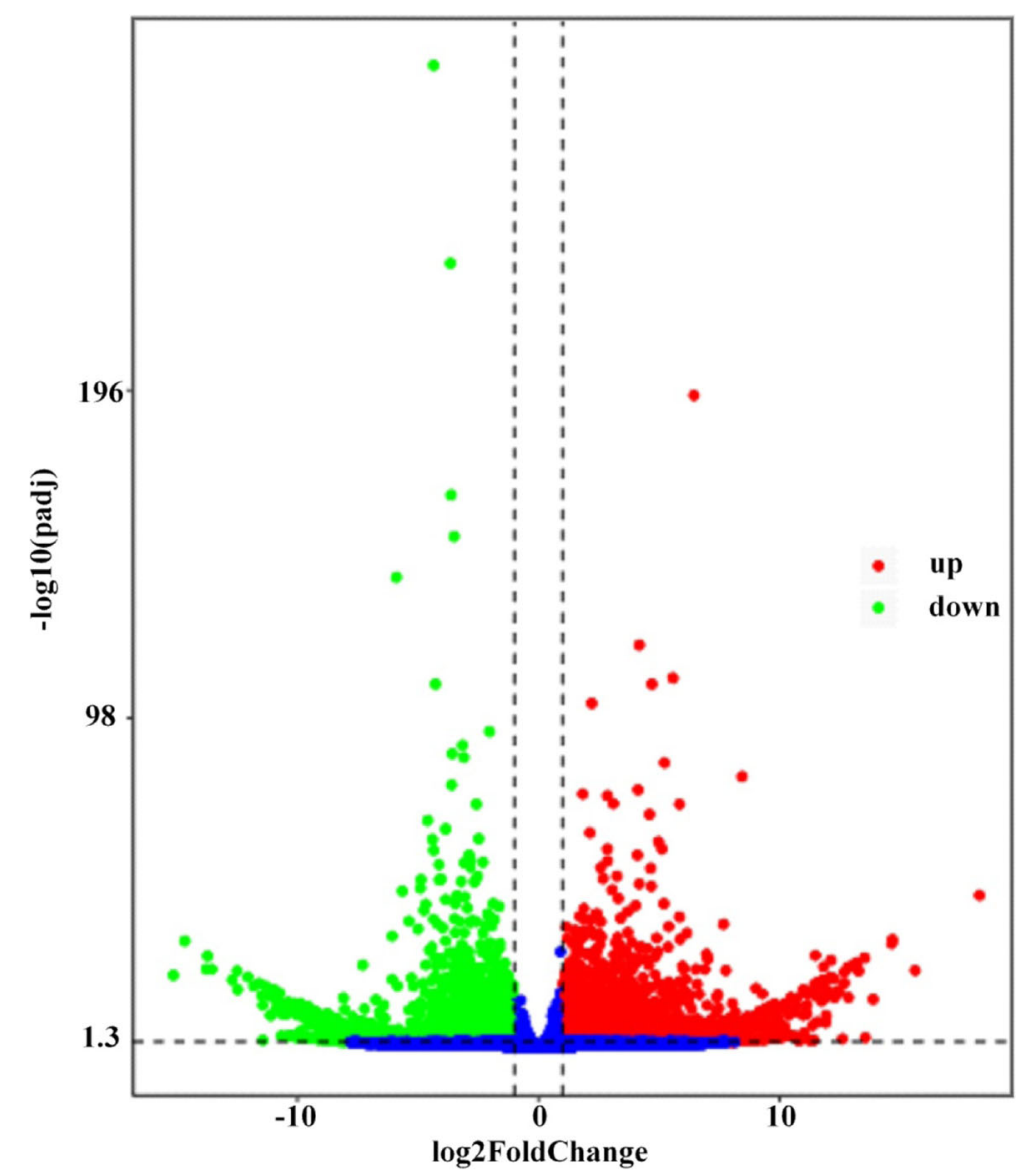

Fig. 5 Volcano plot for global comparison of transcript profiles between germinated and ungerminated spores. Red points indicate up-regulated genes with a threshold of log2FoldChange $>=1$ and padj $<0.05$. Green points indicate down-regulated genes with a threshold of log2FoldChange $<=-1$ and padj $<0.05$ 
Table 3 Spore germination-related gene families

\begin{tabular}{|c|c|c|c|}
\hline Gene family & Gene number & Up-regulated gene number & Down-regulated gene number \\
\hline GPCR & 63 & 18 & 45 \\
\hline G protein alpha subunit & 1 & 1 & 0 \\
\hline Protein kinase & 36 & 19 & 17 \\
\hline Glycoside hydrolase & 76 & 42 & 34 \\
\hline P450 & 102 & 23 & 79 \\
\hline Protease & 234 & 110 & 124 \\
\hline Pectate lyase & 13 & 4 & 9 \\
\hline Cellulase & 8 & 4 & 4 \\
\hline Cutinase & 4 & 1 & 3 \\
\hline Glucanase & 12 & 8 & 4 \\
\hline Glucosidase & 4 & 4 & 0 \\
\hline Xylanase & 2 & 1 & 1 \\
\hline SCRP & 18 & 5 & 13 \\
\hline PKS & 12 & 1 & 11 \\
\hline NRPS & 3 & 0 & 3 \\
\hline NRPS_like & 2 & 1 & 1 \\
\hline Transporter & 243 & 94 & 149 \\
\hline $\mathrm{ABC}$ transporter & 15 & 3 & 12 \\
\hline MFS transporter & 94 & 33 & 61 \\
\hline
\end{tabular}

sampled C. cassiicola isolate. Genome sequencing of the pathogen provided large amounts of important genetic information, which greatly contributed to understanding its evolutionary relationship with other species of phytopathogenic fungi. Additionally, we screened for pathogenicityassociated genes. Many DEGs related to spore germination were identified through RNA-Seq. These results facilitate the study of the pathogenic mechanism of $C$. cassiicola in cucumber.

Phylogenomic analysis showed that C. cassiicola had closer genetic affinity with other fungi of the Pleosporales order than of those not of the Pleosporales order fungi, which was similar to previously reported results [24]. Therefore, it was convenient and efficient to identify novel PHI-associated functional factors of C. cassiicola and study the pathogenic mechanism of $C$. cassiicola based on comparative genomics with other well researched Pleosporales fungi.

As a phytopathogenic fungus, C. cassiicola needs to undergo several crucial and complicated steps to cause host plant disease such as attachment, germination, infection structure formation, invasion and colonization [61]. Fungal pathogens can successfully complete these processes directly via numerous virulence factors, including cutinases, cell wall degrading enzymes, cytomembrane- and cell inclusion-degrading enzymes, mycotoxins, melanin and effectors. The production, transportation and regulation of these virulence factors are mediated by multiple gene pathways, including genes in MAPK, $\mathrm{Ca}^{2+}$ and cAMP pathogenic signal pathways, transcription factors, transporters, core genes for the biosynthesis of secondary metabolites, CYPs, etc. [13]. Moreover, there is cross-talk among multiple pathways, which form an extremely complicated regulatory network. Therefore, the high-throughput identification of PHI-associated genes would accelerate the study of the pathogenic mechanism of C. cassiicola. As expected, thousands of putative virulence-associated genes in various families or pathways were identified in C. cassiicola HGCC, which provided insights into the pathogenic mechanism of C. cassiicola in cucumber. Although HGCC, CCP and UM591 were conspecific and close to each other in relationship, as revealed by phylogenomic analysis, there were differences in sequence features of the genomes among HGCC, CCP and UM591 isolates sampled from different hosts. This phenomenon could be explained by the three isolates evolving and developing specific genetic material to adapt to adverse surroundings, which is worth investigating further.

Fungal infection of plants usually requires contact of conidia with the host and subsequent germination [18]. Conidial germination is a genetically programmed and highly coordinated phenomenon that involves the initiation of biochemical activity, an increase in metabolism and the induction of morphological changes [62, 63]. Isotropic growth, also known as swelling, is the first morphological change of conidial germination, which is 


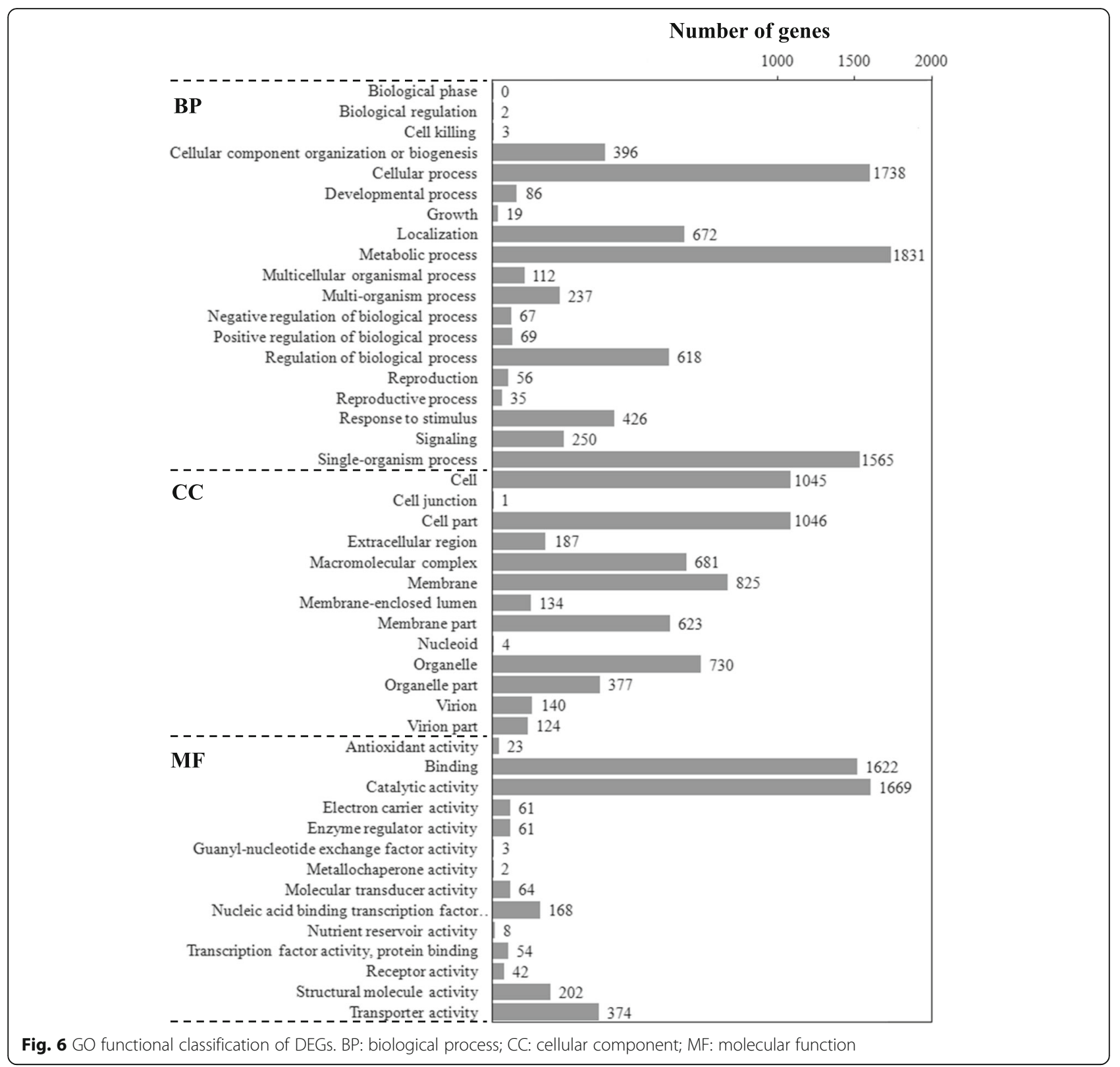

accompanied by water uptake, cell wall growth, cellular composition changes and a decrease in cytoplasmic microviscosity [64], and by many other metabolic activities. After swelling, chitin in the cell wall becomes polarized, and the fungal cell extends at a restricted area at the tip of the cell, which results in the elongation of the germ tube $[65,66]$.

Gene expression profiles can provide insight into the molecular and cellular processes of spore germination at either the transcriptional level or at the proteome level. Zhou et al. found that a total of 3026 genes were differentially expressed during spore germination of Penicillium expansum using RNA-Seq and iTRAQ, and most of them were involved in metabolism and genetic information processing [18]. Liu et al. identified 66 DEGs during spore germination of Nosema bombycis using RNA-Seq [21]. Joise Hander et al. used two-dimensional SDS-PAGE and mass spectrometry to identify a total of 316 spore germination-associated proteins in Moniliophthora perniciosa, including the fungal filamentation associated proteins septin and kinesin, a fumagillin-associated transcription factor and polyketide synthase, ATP synthase, binding immunoglobulin protein (Bip), and catalase [67]. Bassi et al. found 1646 DEGs containing toxinassociated genes nheC, cytK and $h b l C$ during Bacillus thuringiensis spore germination [68]. These research results showed that global transcriptional and protein level analyses were effective tools to understand the molecular 


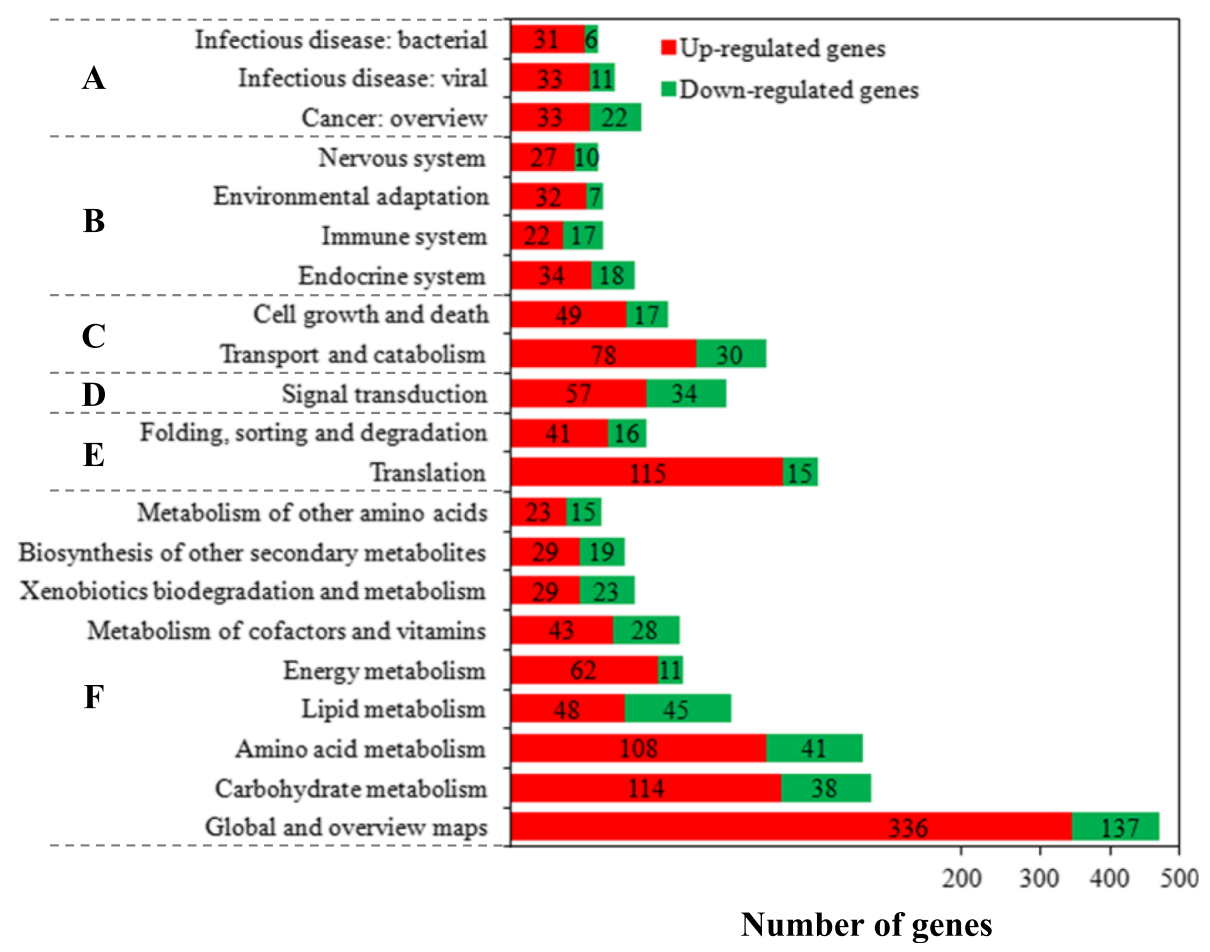

Fig. 7 KEGG classifications of DEGs. The top 20 of the second pathway terms are displayed. $\mathbf{a}, \mathbf{b}, \mathbf{c}, \mathbf{d}$, e and $\mathbf{f}$ indicate the first pathway terms. A: human diseases; $\mathbf{b}$ : organismal systems; c: cellular processes; d: environmental information processing; e: genetic information processing; f: metabolism

and cellular processes of spore germination. Therefore, RNA-Seq was used to explore global gene expression during spore germination of $C$. cassiicola in this study. A total of 3288 genes were found to be differentially expressed, which was similar to the 3026 DEGs observed during spore germination of $P$. expansum [18]. It was found from the GO analysis results of $C$. cassiicola and $P$. expansum that the majority of spore germination-associated DEGs were enriched in cellular processese, localization, metabolic processes, regulation of biological processes, singleorganism processes, binding, and catalytic activity. Similar pathway classification results for DEGs were also found

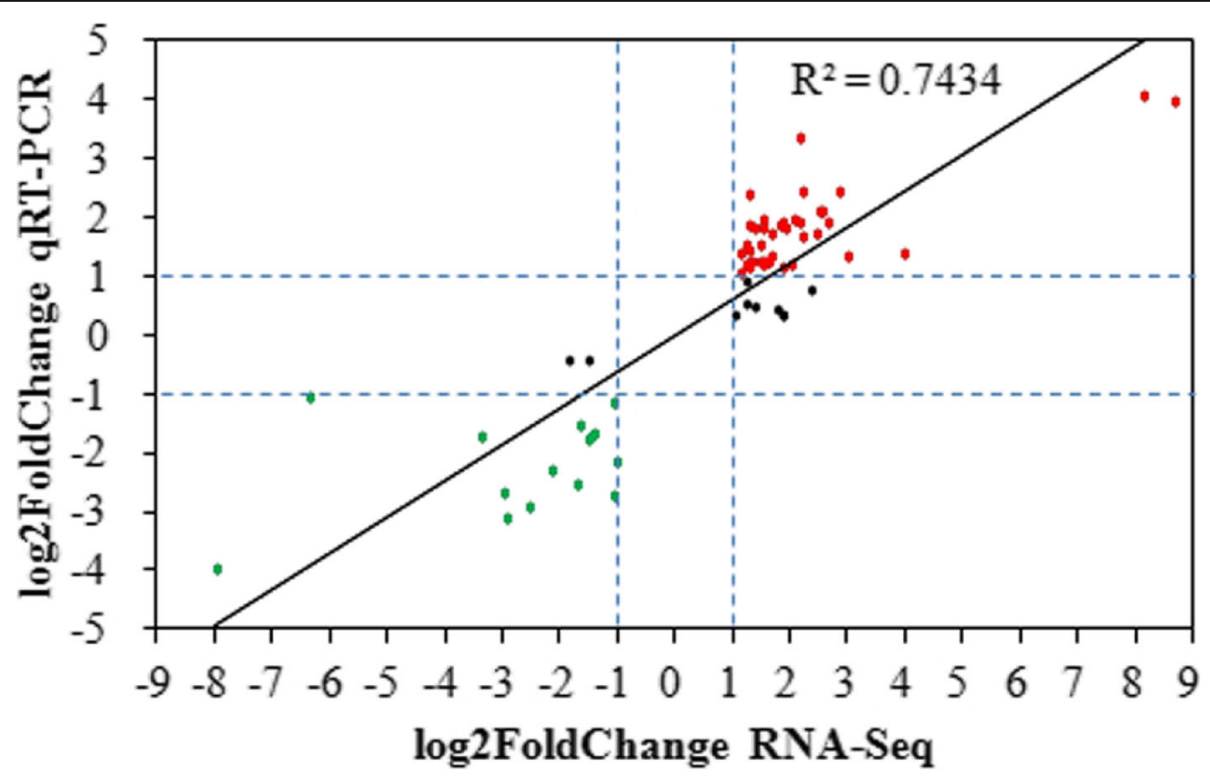

Fig. 8 The correlation of RNA-Seq and qRT-PCR analysis for DEGs 
between $C$. cassiicola and P. expansum, and the majority of KEGG-annotated DEGs were classified in metabolism, genetic information processing, environmental information processing, cellular processes, and human diseases. This phenomenon showed that RNA-Seq data for spore germination were reliable and probably provided valuable information on the molecular mechanism of C. cassiicola germination.

Carbohydrate metabolism involves the various biochemical processes responsible for the formation, breakdown and interconversion of carbohydrates, which serve as short-term fuel for organisms [18]. Therefore, it is not surprising that during a relatively short time of germination, 152 DEGs were involved in carbohydrate metabolism, including glycolysis/gluconeogenesis (29 DEGs), the citrate cycle (12 DEGs), the pentose phosphate pathway (15 DEGs), pentose and glucuronate interconversions (16 DEGs), fructose and mannose metabolism (12 DEGs), galactose metabolism (13 DEGs), ascorbate and aldarate metabolism (9 DEGs), starch and sucrose metabolism (17 DEGs), amino sugar and nucleotide sugar metabolism (24 DEGs), pyruvate metabolism (26 DEGs), glyoxylate and dicarboxylate metabolism (21 DEGs), propanoate metabolism (13 DEGs), butanoate metabolism (17 DEGs), C5-branched dibasic acid metabolism (3 DEGs), and inositol phosphate metabolism (5 DEGs). Most of these DEGs were up-regulated, showing that carbohydrate metabolism was essential for C. cassiicola spore germination. Similar results were found in the spore germination process of Penicillium expansum [18]. Energy metabolism can convert biochemical energy into adenosine triphosphate (ATP). Seventy-three genes were differentially expressed C. cassiicola spore germination, and most of these DEGs were up-regulated, which was nearly opposite to Zhou et al.'s results that all DEGs involved in energy metabolism were down-regulated both in the transcriptional and protein levels [18].

\section{Conclusions}

In conclusion, the genome sequence of $C$. cassiicola from cucumber was presented, and thousands of genome-wide virulence-associated genes were mined by homologous searches against multiple functional databases and conserved domain searches. A total of 3288 genes were differentially expressed during the spore germination of $C$. cassiicola. Most of the KEGG annotated DEGs were involved in metabolism, genetic information processing, cellular processes, organismal system, human diseases and environmental information processing. These results not only facilitate the understanding of the molecular pathogenic mechanism of C. cassiicola in cucumber and the molecular and cellular processes during the spore germination, but also lay the foundation for disease control.

\section{Methods}

Fungal strain, hyphae collection, and DNA isolation

C. cassiicola (Berk. \& M.A. Curtis) strain HGCC, which we isolated from infected cucumber leaves in Shanghai in 2010, was highly virulent to cucumber; thus, it was used for genome sequencing. The isolate was cultured on PDA medium in test tubes at $25^{\circ} \mathrm{C}$ for $7 \mathrm{~d}$ and then maintained at $4^{\circ} \mathrm{C}$. The HGCC isolate was subcultured on PDA plates at $25^{\circ} \mathrm{C}$ in the dark for $10 \mathrm{~d}$, and the mycelium was then collected by peeling it off using a glass slide and ground in liquid nitrogen. Genomic DNA was extracted from finely ground material using the CTAB method [23]. DNA quality control was ensured by $1 \%$ agarose gel electrophoresis and an Infinite M200 PRO instrument (Tecan, Switzerland).

\section{Spore sampling, RNA extraction and sequencing}

Spore production tests were conducted on PDA plates. After being activated on PDA plates at $25^{\circ} \mathrm{C}$, the $\mathrm{HGCC}$ strain was subcultured on PDA plates at $25^{\circ} \mathrm{C}$ for $10 \mathrm{~d}$ with $12 \mathrm{~h}$ of light and $12 \mathrm{~h}$ of dark per day. Five milliliters of sterile $\mathrm{ddH}_{2} \mathrm{O}$ was added to each plate and spores were peeled off using sterile writing brushes and filtered with three layers of sterile gauze to prepare the spore suspension. Spores were collected through centrifugation at $4602 \times \mathrm{g}$ for $5 \mathrm{~min}$. Spores were resuspended and adjusted to $10^{5}$ spores $/ \mathrm{mL}$ with sterile $\mathrm{ddH}_{2} \mathrm{O}$. The spore suspension was incubated at $25^{\circ} \mathrm{C}$ in the dark for $6 \mathrm{~h}$ and $12 \mathrm{~h}$ to perform the spore germination test. Equal volumes of the germinated spore suspensions incubated for $6 \mathrm{~h}$ or $12 \mathrm{~h}$ were mixed. The germinated spores in the mixed suspension were collected by centrifugation at $4602 \times$ g for $5 \mathrm{~min}$. The germinated spores and ungerminated spores were ground for $1 \mathrm{~min}$ using a Geno/Grinder 2010 (SPEX SamplePrep, USA) after being frozen rapidly with liquid nitrogen for the extraction of total RNA. Total RNA was extracted using the TaKaRa MiniBEST universal RNA extraction kit following the manufacturer's recommended method and stored at $-80^{\circ} \mathrm{C}$. The test was conducted in biological triplicate.

Total RNA was quantified and assessed for purity using a Nanodrop instrument, and the integrity was evaluated using an Agilent 2100 instrument. RNA samples returning an RNA integrity number (RIN) greater than 6.3 were considered acceptable for sequencing. A cDNA library was made from each qualified RNA sample. The libraries were sequenced using an Illumina HiSeq X 10 instrument at the Novogene Bioinformatics Institute, Beijing.

\section{Whole genome shotgun sequencing and assembly}

The whole genome of HGCC was de novo sequenced using an Illumina HiSeq $\mathrm{X}$ Ten in $2 \times 149$ bp paired-end mode with a $400 \mathrm{bp}$ insert sizes of the library at Personalbio 
(Shanghai, China). High-quality data were obtained from raw data by removing adapter contamination with AdapterRemoval (version 2) [69], collection with SOAPec (version 2.01) [70], and length screening with a threshold of $>50 \mathrm{bp}$. These high-quality data were de novo assembled using SPAdes v3.9.0 [71]. This whole genome shotgun project was deposited at DDBJ/ENA/GenBank under the accession number RJLO00000000. The version described in this paper is version RJLO01000000.

Gene prediction, annotation, identification of orthologous gene, and interspecific phylogenomic analysis

Gene structures of $C$. cassiicola genome sequences were predicted using Augustus software with the annotated gene information of $B$. cinerea [72]. Putative secreted proteins were identified by combining Target 1.1 [73], SignalP 4.1 Server [74], TMHMM Server v. 2.0 [75], and Big-GPI software [76]. Putative SCRPs were screened from secreted proteins based on their sequence characteristics such as 20-150 amino acids and at least four cysteines [77]. Protein family classification of C. cassiicola was performed by sequence alignment against the Pfam database with profile hidden Markov models (http://xfam.org/) using hmmer $3.1 \mathrm{~b} 2$ (http://www. hmmer.org/).

Potential virulence-associated genes were identified by local BLASTP searches of C. cassiicola HGCC protein sequences against the PHI database (version 4.4, http:// www.phi-base.org/) with a cutoff $E$-value of 1e-5. MAPK pathway associated genes of $C$. cassiicola were screened by local BLASTP against $S$. cerevisiae MAPK pathwayassociated genes with a cutoff $E$-value of $1 \mathrm{e}-5$ that were confirmed by experiments. GPCRs were identified by local BLASTP against the GPCRDB database (http:// gpcrdb.org/) with the best hits and further confirmed by searching seven transmembrane helices with TMHMM Server v. 2.0. Kinases, proteases and transporters were identified by local BLASTP against the KinBase database with a cutoff $E$-value of 1e-10, the MEROPS peptidase database (https://www.ebi.ac.uk/merops/) with a cutoff $E$-value of 1e-20 [78], and the Transporter Classification Database (TCDB) [79] with a cutoff $E$-value of 1e-40, respectively [80]. CYPs and GHs families were classified based on BLASTP alignment against the P450 database (http://drnelson.uthsc.edu/CytochromeP450.html) and CAZy database (http://www.cazy.org/), respectively, with a cutoff $E$-value of 1e-10.

Secondary metabolism backbone genes such as PKS, NRPS and NRPS-PKS were identified in the SMURF system (http://smurf.jcvi.org/index.php) [81]. C. cassiicola PKSs and other functionally known PKSs in other fungi were submitted to the SBSPKS database (http://www.nii.ac. in/ pksdb/sbspks/master.html) to modulate and analyze conserved domains. Phylogenetic analysis of PKSs was performed by aligning KS domain sequences and creating a maximum likelihood tree using MEGA 7.0 with JonesTaylor-Thornton (JTT) model. These functionally known PKS-related toxin biosynthesis pathways included A. ochraceus AoLC35-12 (GenBank: AAT92023) for ochratoxin production, A. alternate ACTTS3 (GenBank: BAJ14522) for ACT-toxin production, B. maydis PKS1 (GenBank: AAB08104) and PKS2 (GenBank: AAR90257) for T-toxin production, G. zeae PKS4 (GenBank: ABB90283) for zearalenones production and G. moniliformis Fum1p (GenBank: AAD43562) for fumonisin production. Melanin-associated PKSs included A. fumigatus Alb1p (GenBank: ACJ13039), Ceratocystis resinifera PKS1 (GenBank: AAO60166), C. lagenarium PKS1 (GenBank: BAA18956), C. globosum PKS-1 (GenBank: AFP82905), A. rabie PKS1 (GenBank: ACS74449), B. maydis PKS18 (GenBank: AAR90272), S. turcica StPKS (GenBank: AEE68981), B. oryzae PKS1 (GenBank: BAD22832), and A. alternate ALM1 (GenBank: BAK64048).

To compare the gene annotation between C. cassiicola HGCC and the other two C. cassiicola isolates (UM591 and $\mathrm{CCP}$ ) or other phytopathogenic fungi, the same pipeline was used for the gene prediction and annotation of the genome for all species. Accession numbers of the genomes are JAQF00000000.1 (GenBanK) for C. cassiicola UM591, GCA_003016335.1 (GenBanK) for C. cassiicola CCP, GCA_000743335.1 (GenBanK) for C. lunata, GCA_000338975.1 (GenBanK) for B. maydis, 2, 761,201,826 (JGI) for C. zeae-maydis, GCA_002267025.1 (GenBanK) for P. nodorum, GCA_000359705.1 (GenBanK) for S. turcica, GCA_000149985.1 (GenBanK) for P. tritici-repentis, GCA_000002495.2 (GenBanK) for $M$. oryzae, GCA_009017415.1 (GenBanK) for A. flavus, GCA_000240135.3 (GenBanK) for F. graminearum, and GCA_000143535.4 (GenBanK) for B. cinerea. To construct an interspecific phylogenetic tree among these fungi, 2831 orthologous protein sequences were screened by local reciprocal Blast search with a cutoff of $E$-value 1e-20. These orthologous proteins were aligned using Clustal W 2.1 [82]. A maximum likelihood tree was created by the concatenated amino acid sequences using MEGA7.0 with the JTT model.

Statistical analysis was conducted by a non-parametric test (Mann-Whitney U test) of SSPS v18.0 using the gene amount of each gene family in C. cassiicola (HGCC, CCP and UM591) compared to 10 other phytopathogenic fungi, including $C$. lunata, B. maydis, $C$. zeae-maydis, P. nodorum, S. turcica, P. tritici-repentis, $M$. oryzae, A. flavus, F. graminearum, and B. cinerea. The cutoff of significance was set at $P<0.05$.

\section{Gene expression in spore germination in C. cassiicola}

The quality of the raw reads generated from RNA-Seq was checked with FastQC [83]. The clean reads were 
obtained from the raw reads by removing adapters containing reads, $>10 \%$ " $\mathrm{N}$ " containing reads, and reads of low quality. The 6 trimmed C. cassiicola RNA-Seq libraries were mapped on the predicted CDS of C. cassiicola using Bowtie2 with default settings [84]. The number of reads mapped to each gene for each RNA set was calculated from the sam alignment files derived from Bowtie2. The data of RNA-Seq has been deposited at DDBJ/ENA/ GenBank under the SRA accession PRJNA626372.

The counts of RNA-Seq reads over transcripts were used to calculate the fold change of gene expression using DESeq2 [85]. DEGs were selected by the cutoffs on both padj and log2FoldChange. Genes were considered differentially expressed if padj $<0.05$ and $\mid \log 2$ FoldChange| $>1$. Pathway enrichments of DEGs were performed with the KEGG database.

\section{Quantitative real-time PCR (qRT-PCR) assays}

Sixty-six DEGs involved in the cell growth and death of cellular processes were selected for the confirmation of the RNA-Seq data using qRT-PCR (Table S18 in Additional file 2). The Gapdh gene was used as the internal control. The first strand of cDNA was synthesized from total RNA of germinated and ungerminated spores using EasyScript All-in-One First-Strand cDNA Synthesis SuperMix for qPCR (One-Step gDNA Removal) (Transgen, China). The qRT-PCR test was conducted with a QuanStudio 6 Flex instrument (Thermo Fisher Scientific, USA). Twenty microliters of reaction mixture contained $2 \mu \mathrm{L}$ diluted cDNA (1-100 ng), $0.4 \mu \mathrm{L}$ of each primer $(10 \mu \mathrm{M}), 7.2 \mu \mathrm{L}$ of nuclease-free water and $10 \mu \mathrm{L}$ of $2 \times$ TransStart $^{\circ}$ Top Green qPCR SuperMix (Transgen, China). The reaction program was follows: one cycle at $94{ }^{\circ} \mathrm{C}$ for $30 \mathrm{~s}$ and 40 cycles at $94{ }^{\circ} \mathrm{C}$ for $5 \mathrm{~s}, 60^{\circ} \mathrm{C}$ for $15 \mathrm{~s}$ and $72{ }^{\circ} \mathrm{C}$ for $10 \mathrm{~s}$. The specificities of the amplification products were tested through a melting-curve analysis between $60{ }^{\circ} \mathrm{C}$ and $95^{\circ} \mathrm{C}$ after each PCR reaction. The relative gene expression data were analyzed using the $2^{-\Delta \Delta \mathrm{Ct}}$ method [86]. These qRT-PCR assays were performed with three biological and three technical replicates.

\section{Supplementary information}

Supplementary information accompanies this paper at https://doi.org/10. 1186/s12866-020-01873-w.

Additional file 1: Table S1 The numbers of genes and PHI-associated genes in C. cassiicola and other ascomycetes. Fungal species: HGCC, C. cassiicola HGCC; CCP, C. cassiicola CCP; UM591, C. cassiicola UM591; CL, C. lunata; BM, B. maydis; CZM, C. zeae-maydis; PN, P. nodorum; ST, S. turcica; PTR, P. tritici-repentis; MO, M. oryzae; AF, A. flavus; FG, F. graminearum; BC, B. cinerea. ${ }^{a}$ Average is calculated using the gene amount in the 10 other plant pathogenic fungi (grey column). ${ }^{b} P$ value (highlighted in bold for comparisons showing significant differences) is calculated by a nonparametric test (Mann-Whitney $U$ test) of SSPS v18.0 using the gene amount of each family in C. cassiicola (HGCC, CCP and UM591) compared to the 10 other plant pathogenic fungi (grey column). The cutoff of significance is set at $P<0.05$ (highlighted). ${ }^{C} \mathrm{PHI}$ : pathogen-host interaction. d Percentage: The percentage of $\mathrm{PHI}$-associated gene in protein-coding genes. Table $\mathbf{S 2}$ The number of genes for selected gene families in C. cassiicola and other ascomycetes. ${ }^{a}$ PHI: pathogen-host interaction. ${ }^{b}$ Average is calculated using the gene/PHI-associated gene amount of each family in the 10 other plant pathogenic fungi (grey column). ${ }^{c} p$ value (highlighted in bold for comparisons showing significant differences) is calculated by a non-parametric test (Mann-Whitney $U$ test) of SSPS v18.0 using the gene amount of each family in C. cassiicola (HGCC, CCP and UM591) compared to the 10 other plant pathogenic fungi (grey column). The cutoff of significance is set at $P<0.05$ (highlighted). Fungal species: HGCC, C. cassiicola HGCC; CCP, C. cassiicola CCP; UM591, C. cassiicola UM591; CL, C. lunata; BM, B. maydis; CZM, C. zeae-maydis; PN, P. nodorum; ST, S. turcica; PTR, P. tritici-repentis; MO, M. oryzae; AF, A. flavus; FG, F. graminearum; BC, B. cinerea. Table S3 G protein-coupled receptors in different fungal genomes. ${ }^{a} \mathrm{PHI}$ : pathogen-host interaction. ${ }^{\mathrm{b}}$ Average is calculated using the gene/PHI-associated gene amount of each family in the 10 other plant pathogenic fungi (grey column). ${ }^{c} P$ value (highlighted in bold for comparisons showing significant differences) is calculated by a non-parametric test (Mann-Whitney $U$ test) of SSPS v18.0 using the gene amount of each family in C. cassiicola (HGCC, CCP and UM591) compared to the 10 other plant pathogenic fungi (grey column). The cutoff of significance is set at $P<0.05$ (highlighted). Fungal species: HGCC, C. cassiicola HGCC; CCP, C. cassiicola CCP; UM591, C. cassiicola UM591; CL, C. lunata; BM, B. maydis; CZM, C. zeae-maydis; PN, P. nodorum; ST, S. turcica; PTR, P. tritici-repentis; MO, M. oryzae; AF, A. flavus; FG, F. graminearum; BC, B. cinerea. Table S4 Gene-encoding proteins for the MAPK signaling pathway in C. cassiicola HGCC. The colour of the protein names indicates the degree of conservation between S. cerevisiae and C. cassiicola HGCC proteins based on Blastp. Blue, e-value $<1 \mathrm{e}-5$ and $>1 \mathrm{e}-20$; Green, e-value <1e-100 and > 1e-20; Red, e-value <1e-100. Table S5 Gene-encoding proteins for the CAMP signaling pathway in C. cassiicola HGCC. Table $\mathbf{5} 6$ Gene-encoding proteins for the $\mathrm{Ca}^{2+}$ signaling pathway in C. cassiicola HGCC. Table S7 The number of protein kinases in different fungal genomes. ${ }^{a} \mathrm{PHI}$ : pathogen-host interaction. ${ }^{\mathrm{b}}$ Average is calculated using the gene/ $\mathrm{PHI}$-associated gene amount of each family in the 10 other plant pathogenic fungi (grey column). ${ }^{c} P$ value (highlighted in bold for comparisons showing significant differences) is calculated by a non-parametric test (Mann-Whitney $U$ test) of SSPS v18.0 using the gene amount of each family in C. cassiicola (HGCC, CCP and UM591) compared to the 10 other plant pathogenic fungi (grey column). The cutoff of significance is set at $P<0.05$ (highlighted). Fungal species: HGCC, C. cassiicola HGCC; CCP, C. cassiicola CCP; UM591, C. cassiicola UM591; CL, C. lunata; BM, B. maydis; CZM, C. zeae-maydis; PN, P. nodorum; ST, S. turcica; PTR, P. tritici-repentis; MO, M. oryzae; AF, A. flavus; FG, F. graminearum; BC, $B$. cinerea. Table $\mathbf{S 8}$ Protease genes classified by the MEROPS family in different fungal genomes. ${ }^{a}$ PHI: pathogen-host interaction. ${ }^{b}$ Average is calculated using the gene/PHI-associated gene amount of each family in the 10 other plant pathogenic fungi (grey column). ${ }^{c} p$ value (highlighted in bold for comparisons showing significant differences) is calculated by a non-parametric test (Mann-Whitney $U$ test) of SSPS v18.0 using the gene amount of each family in C. cassiicola (HGCC, CCP and UM591) compared to the 10 other plant pathogenic fungi (grey column). The cutoff of significance is set at $P<0.05$ (highlighted). Fungal species: HGCC, C. cassiicola HGCC; CCP, C. cassiicola CCP; UM591, C. cassiicola UM591; CL, C. lunata; BM, B. maydis; CZM, C. zeae-maydis; PN, P. nodorum; ST, S. turcica; PTR, P. tritici-repentis; MO, M. oryzae; AF, A. flavus; FG, F. graminearum; BC, B. cinerea. Table $\mathbf{S 9}$ Glycoside hydrolase in C. cassiicola and other phytopathogenic ascomycetes. ${ }^{a}$ PHI: pathogen-host interaction. ${ }^{b}$ Average is 
calculated using the gene/PHI-associated gene amount of each family in the 10 other plant pathogenic fungi (grey column). ${ }^{c} P$ value (highlighted in bold for comparisons showing significant differences) is calculated by a non-parametric test (Mann-Whitney $U$ test) of SSPS V18.0 using the gene amount of each family in C. cassiicola (HGCC, CCP and UM591) compared to the 10 other plant pathogenic fungi (grey column). The cutoff of significance is set at $P<0.05$ (highlighted). Fungal species: HGCC, $C$. cassiicola HGCC; CCP, C. cassiicola CCP; UM591, C. cassiicola UM591; CL, C. lunata; BM, B. maydis; CZM, C. zeae-maydis; PN, P. nodorum; ST, S. turcica; PTR, P. tritici-repentis; MO, M. oryzae; AF, A. flavus; FG, F. graminearum; BC, B. cinerea. Table S10 Transporters in C. cassiicola and other phytopathogenic ascomycetes. ${ }^{\text {a }} \mathrm{PHI}$ : pathogen-host interaction. ${ }^{\mathrm{b}}$ Average is calculated using the gene/PHI-associated gene amount of each family in the 10 other plant pathogenic fungi (grey column). ${ }^{c} p$ value (highlighted in bold for comparisons showing significant differences) is calculated by a non-parametric test (Mann-Whitney $U$ test) of SSPS V18.0 using the gene amount of each family in C. cassiicola (HGCC, CCP and UM591) compared to the 10 other plant pathogenic fungi (grey column). The cutoff of significance is set at $P<0.05$ (highlighted). Fungal species: HGCC, C. cassiicola HGCC; CCP, C. cassiicola CCP; UM591, C. cassiicola UM591; CL, C. lunata; BM, B. maydis; CZM, C. zeae-maydis; PN, P. nodorum; ST, S. turcica; PTR, P. tritici-repentis; MO, M. oryzae; AF, A. flavus; FG, F. graminearum; BC, B. cinerea. Table S11 Drug transporters in C. cassiicola and other phytopathogenic ascomycetes. ${ }^{a} \mathrm{PHI}$ : pathogen-host interaction. ${ }^{\mathrm{b}}$ Average is calculated using the gene/PHI-associated gene amount of each family in the 10 other plant pathogenic fungi (grey column). ${ }^{C} P$ value (highlighted in bold for comparisons showing significant differences) is calculated by a non-parametric test (Mann-Whitney $U$ test) of SSPS v18.0 using the gene amount of each family in C. cassiicola (HGCC, CCP and UM591) compared to the 10 other plant pathogenic fungi (grey column). The cutoff of significance is set at $P<0.05$ (highlighted). Fungal species: HGCC, C. cassiicola HGCC; CCP, C. cassiicola CCP; UM591, C. cassiicola UM591; CL, C. lunata; BM, B. maydis; CZM, C. zeae-maydis; PN, P. nodorum; ST, S. turcica; PTR, P. tritici-repentis; MO, M. oryzae; AF, A. flavus; FG, F. graminearum; BC, B. cinerea. Table S12 Cytochrome P450 genes classified by the CYP family in different fungal genomes. ${ }^{\mathrm{a}} \mathrm{PHI}$ : pathogen-host interaction. ${ }^{\mathrm{b}}$ Average is calculated using the gene/PHI-associated gene amount of each family in the 10 other plant pathogenic fungi (grey column). ${ }^{c} p$ value (highlighted in bold for comparisons showing significant differences) is calculated by a non-parametric test (Mann-Whitney $\mathrm{U}$ test) of SSPS v18.0 using the gene amount of each family in C. cassiicola (HGCC, CCP and UM591) compared to the 10 other plant pathogenic fungi (grey column). The cutoff of significance is set at $P<0.05$ (highlighted). Fungal species: HGCC, C. cassiicola HGCC; CCP, C. cassiicola CCP; UM591, C. cassiicola UM591; CL, C. lunata; BM, B. maydis; CZM, C. zeae-maydis; PN, P. nodorum; ST, S. turcica; PTR, P. tritici-repentis; MO, M. oryzae; AF, A. flavus; FG, F. graminearum; BC, B. cinerea. Table $\mathbf{S 1 3}$ Numbers of backbone genes for the biosynthesis of secondary metabolites in different pathogenic fungi. ${ }^{\text {a }}$ PHI: pathogen-host interaction. ${ }^{b}$ Average is calculated using the gene/ PHI-associated gene amount of each family in the 10 other plant pathogenic fungi (grey column). ${ }^{c} P$ value (highlighted in bold for comparisons showing significant differences) is calculated by a non-parametric test (Mann-Whitney $U$ test) of SSPS V18.0 using the gene amount of each family in C. cassiicola (HGCC, CCP and UM591) compared to the 10 other plant pathogenic fungi (grey column). The cutoff of significance is set at $P<0.05$ (highlighted). Fungal species: HGCC, C. cassiicola HGCC; CCP, C. cassiicola CCP; UM591, C. cassiicola UM591; CL, C. lunata; BM, B. maydis; CZM, C. zeae-maydis; PN, P. nodorum; ST, S. turcica; PTR, P. tritici-repentis; MO, M. oryzae; AF, A. flavus; FG, F. graminearum; BC, B. cinerea. Table S14 Putative small, cysteine-rich proteins (SCRPS) in C. cassiicola HGCC.
Additional file 2: Table S15 Sequencing yield from individual libraries per sample. ${ }^{a}$ CC_0_1, ${ }^{b}$ CC_0_2 and ${ }^{C}$ CC_0_3 are triplicate ungerminated spore samples. ${ }^{\mathrm{d}}$ CC 6 _ $12, \overline{1},{ }^{\mathrm{e}} \mathrm{CC}$ 6_12_2, and ${ }^{\mathrm{f}}$

CC_6_12_3 are triplicate mixed $6 \mathrm{~h}$ - and $12 \mathrm{~h}$-germinated spore samples. Table S16 3288 DEGs during spore germination identified by RNA-Seq. ${ }^{\text {a }}$ CC_6_12: mixed $6 \mathrm{~h}$ - and $12 \mathrm{~h}$-germinated spore samples; ${ }^{\mathrm{b}}$ CC_0: ungerminated spore samples. Table S17 KEGG pathway enrichment analysis of DEGs. Table S18 qRT-PCR for selected DEGs involved in cell growth and death. ${ }^{*}$ The express pattern of DEGs from RNA-Seq was not validated by qRT-PCR.

Additional file 3: Fig. S1 Pearson correlation between samples in gene expression levels. CC_0_1, CC_0_2 and CC_0_3 are triplicate ungerminated spore samples. CC_6_12_1, CC_6_12_2, and CC_6_12_3 are triplicate mixed $6 \mathrm{~h}$ - and $12 \mathrm{~h}$-germinated spore samples. $\mathrm{R}^{\overline{2}}$ is the square of the Pearson correlation coefficient.

\section{Abbreviations}

MAPK: Mitogen-activated protein kinase; GPCR: G-protein-coupled receptor; PHI: Pathogen-host interaction; GH: Glycoside hydrolase; ABC: ATP-binding cassette; MFS: Major facilitator superfamily; DHA: Drug: $\mathrm{H}+$ antiporter; MDR: Multidrug resistance; PDR: Pleiotropic drug resistance; CYP: Cytochrome P450 enzyme; NRPS: Non-ribosomal peptide synthetase; PKS: Polyketone synthase; HK: Histidine kinase; DMAT: Dimethylallyl tryptophan synthase; HYBRID: Hybrid PKS-NRPS enzyme; KS: Ketoacyl CoA synthase; AT: Acyltransferase; DH: Dehydratase; ER: Enoyl reductase; KR: Ketoreductase; SCRP: Small cysteine-rich protein; HR: Hypersensitive response; PAMP: Pathogen-associated molecular pattern; PTI: PAMP-triggered immunity; ETI: Effector-triggered immunity; LysM: Lysin motif; CFEM: Common in fungal extracellular membrane; KEGG: Kyoto Encyclopaedia of Genes and Genomes; DEG: Differentially expressed gene; CDS: Coding sequence

\section{Acknowledgements}

Not applicable.

\section{Authors' contributions}

SG conducted the submission of sequencing data, the classification of protein family, the identification of functional genes, and drafted the manuscript. RZ carried out DNA and total RNA extraction, sequencingassociated works, and phylogenetic analysis. LX took charge qRT-PCR. ZS and $P G$ revised the manuscript. FD conceived the study and designed the article contents. All authors had read and approved the final manuscript.

\section{Funding}

This work, including the design of the study, sequencing, qRT-PCR, annotation and interpretation of data, and writing the manuscript, was financially supported by Natural Science Foundation of Shanghai (Grant No. 16ZR1424100), SAAS Program for Excellent Research Team (Grant No. 2017(A03)), China National Major Program of Science and Technology (Grant No. 2017ZX07202004-004), and Shanghai Rising-Star Program (Grant No. 17QB1403200).

\section{Availability of data and materials}

The data that support the findings of this study are available from [https:// www.ncbi.nIm.nih.gov/genome/, Accession No. RJLO00000000] and [https:// www.ncbi.n/m.nih.gov/sra/PRJNA626372] but restrictions apply to the availability of these data, which were used under license for the current study, and so are not publicly available. Data are however available from the authors upon reasonable request and with permission of [https://www.ncbi. nlm.nih.gov/genome/, Accession No. RJLO00000000] and [https://www.ncbi. nlm.nih.gov/sra/PRJNA626372]

The dataset(s) supporting the conclusions of this article is (are) included within the article (and its additional file(s)).

Ethics approval and consent to participate Not applicable.

Consent for publication

Not applicable 


\section{Competing interests}

The authors declare no competing financial and non-financial interests.

\section{Received: 4 May 2020 Accepted: 24 June 2020}

Published online: 08 July 2020

\section{References}

1. Li BJ, Gao W, Shi YX, Xie XW. Progress in researches on Corynespora leaf spot. Acta Phytophy Sin. 2012;39(2):171-6.

2. Sumabat L, Kemerait RC, Brewer MT. Phylogenetic diversity and host specialization of Corynespora cassiicola responsible for emerging target spot disease of cotton and other crops in the southeastern United States. Phytopathology. 2018;108(7):892-901.

3. Chung SR, Lee HS, You IC. Fungal keratitis caused by Corynespora cassiicola, a plant pathogen. J Mycol Infect. 2018;23(1):24-6.

4. Xie ZL, Wu W, Meng DS, Zhang Q, Ma YQ, Liu W, Chen JH. A case of Phaeohyphomycosis caused by Corynespora cassiicola infection. BMC Infect Dis. 2018;18(1):444.

5. Liu MT, Zhang DF, Sun HT. Studies on the biological characteristics of Corynespora cassiicola. China Vegetables. 2003;20(2):93-102.

6. Liu D, Qin Z, Zhang Y, Zhou X, Xin M. Histological observation of cucumber infected with Corynespora cassiicola. Eur J Plant Pathol. 2017;149(2):455-66.

7. Dixon L, Schlub RL, Pernezny K, Datnoff LE. Host specialization and phylogenetic diversity of Corynespora cassiicola. Phytopathology. 2009;99(9): 1015.

8. Shimomoto Y, Sato T, Hojo H, Morita Y, Takeuchi S, Mizumoto H, Kiba A, Hikichi Y. Pathogenic and genetic variation among isolates of Corynespora cassiicola in Japan. Plant Pathol. 2015:60(2):253-60.

9. Barthe P, Pujaderenaud V, Breton F, Gargani D, Thai R, Roumestand C, De FL. Structural analysis of cassiicolin, a host-selective protein toxin from Corynespora cassiicola. J Mol Biol. 2007;367(1):89-101.

10. Déon M, Fumanal B, Gimenez S, Bieysse D, Oliveira RR, Shuib SS, Breton F, Elumalai $S$, Vida JB, Seguin M. Diversity of the cassiicolin gene in Corynespora cassiicola and relation with the pathogenicity in Hevea brasiliensis. Fungal Biol-UK. 2014;118(1):32-47.

11. Wu J, Xie X, Shi Y, Chai A, Wang Q, Li B. Erratum to: variation of cassiicolin genes among Chinese isolates of Corynespora cassiicola. J Microbiol. 2018; 56(9):691.

12. Liu ZH, Ye Ql, Huang XY, Yang H, Hou Y, Zhang R. Conditions and activity analysis of cell wall degrading enzymes produced from Corynespora cassiicola of brown spot of cucumber. China Vegetables. 2011.

13. Dean RA, Talbot NJ, Ebbole DJ, Farman ML, Mitchell TK, Orbach MJ, Thon M, Kulkarni $\mathrm{R}$, Xu JR, Pan $\mathrm{H}$, et al. The genome sequence of the rice blast fungus Magnaporthe grisea. Nature. 2005;434(7036):980-6.

14. Liu XM, Pu JJ, Zhang X, Qi YX, Xie YX, Zhang H, Zheng FC. Cloning and bioinformatics analysis of gene CCK1 related to pathogenicity of Corynespora cassiicola on Hevea rubber. Biotechnol Bull 2012; 0(10):168-172.

15. Qi YX, Zhang X, Pu JJ, Lu Y, Zhang H, Zhang HQ, Xie YX. Cloning and sequence analysis of a Slt2-type MAPK homologous gene CMP1 from Corynespora cassiicola of Hevea brasiliensis. Chinese J Trop Crop. 2010; 31(11):1951-8.

16. Liu XM, Zheng FC, Zhang X, Qi YX, Xie YX, Zhang H, Pu JJ. Cloning and pathogenicity of toxin gene cc004-cas from Corynespora cassiicola on Hevea brasiliensis. Chinese J Trop Crop. 2014;35(9):1809-15.

17. Déon M, Bourré Y, Gimenez S, Berger A, Bieysse D, De LF, Poncet J, Roussel $\mathrm{V}$, Bonnot $\mathrm{F}$, Oliver $\mathrm{G}$. Characterization of a cassiicolin-encoding gene from Corynespora cassiicola, pathogen of rubber tree (Hevea brasiliensis). Plant Sci. 2012;185-186(4):227-37.

18. Zhou T, Wang X, Luo J, Ye B, Zhou Y, Zhou L, Lai T. Identification of differentially expressed genes involved in spore germination of Penicillium expansum by comparative transcriptome and proteome approaches. Microbiologyopen. 2018;7(3):e00562.

19. Leeuwen MRV, Krijgsheld P, Bleichrodt R, Menke H, Stam H, Stark J, Wösten $\mathrm{HAB}$, Dijksterhuis J. Germination of conidia of Aspergillus niger is accompanied by major changes in RNA profiles. Stud Mycol. 2013;74(1):59-70.

20. Dague E, Alsteens D, Latgé JP, Dufrêne YF. High-resolution cell surface dynamics of germinating Aspergillus fumigatus conidia. Biophys J. 2008;94(2):656-60.

21. Liu H, Li M, He X, Cai S, He X, Lu X. Transcriptome sequencing and characterization of ungerminated and germinated spores of Nosema bombycis. Acta Biochim Biophys Sin. 2016;48(3):246-56.
22. Nagler K, Krawczyk AO, De Jong A, Madela K, Hoffmann T, Laue M, Kuipers $\mathrm{OP}$, Bremer E, Moeller R. Identification of differentially expressed genes during Bacillus subtilis spore outgrowth in high-salinity environments using RNA sequencing. Front Microbiol. 2016;7:1564.

23. Gao SG, Li YQ, Gao JX, Suo YJ, Fu KH, Li YY, Chen J. Genome sequence and virulence variation-related transcriptome profiles of Curvularia lunata, an important maize pathogenic fungus. BMC Genomics. 2014;15(1):627.

24. Lopez D, Ribeiro S, Label P, Fumanal B, Venisse JS, Kohler A, De RO, Labutti K, Lipzen A, Lail K. Genome-wide analysis of Corynespora cassiicola leaf fall disease putative effectors. Front Microbiol. 2018;9:276.

25. Hong KL, Yue FT, Su MY, Ling S, Kuan CS. Genomic insight into pathogenicity of dematiaceous fungus Corynespora cassiicola. Peerj. 2017;5(19):e2841.

26. Affeldt KJ, Carrig J, Amare M, Keller NP. Global survey of canonical Aspergillus flavus G protein-coupled receptors. Mbio. 2014;5(5):01501-14.

27. Li L, Wright SJ, Krystofova S, Park G, Borkovich KA. Heterotrimeric G protein signaling in filamentous fungi. Annu Rev Microbiol. 2007;61(1):423.

28. DeZwaan TM, Carroll AM, Valent B, Sweigard JA. Magnaporthe grisea pth11p is a novel plasma membrane protein that mediates appressorium differentiation in response to inductive substrate cues. Plant Cell. 1999;11 (10):2013-30.

29. Preininger AM, Hamm HE. G protein signaling: insights from new structures. Sci STKE. 2004(218):re3.

30. Svoboda P, Teisinger J, Novotny J, Bourova L, Drmota T, Hejnova L, Moravcova Z, Lisy V, Rudajev V, Stohr J, et al. Biochemistry of transmembrane signaling mediated by trimeric $\mathrm{G}$ proteins. Physiol Res. 2004;53(Suppl 1):S141-52.

31. Yu HY, Seo JA, Kim JE, Han KH, Shim WB, Yun SH, Lee YW. Functional analyses of heterotrimeric $\mathrm{G}$ protein $\mathrm{G}$ alpha and $\mathrm{G}$ beta subunits in Gibberella zeae. Microbiol. 2008;154(Pt 2):392-401.

32. Rispail N, Di PA. The two-component histidine kinase Fhk1 controls stress adaptation and virulence of Fusarium oxysporum. Mol Plant Pathol. 2010; 11(3):395-407.

33. Ochiai N, Tokai T, Nishiuchi T, Takahashi-Ando N, Fujimura M, Kimura M. Involvement of the osmosensor histidine kinase and osmotic stressactivated protein kinases in the regulation of secondary metabolism in Fusarium graminearum. Biochem Bioph Res Co. 2007;363(3):639-44.

34. Gui Y, Zhang W, Zhang D, Zhou L, Short D, Wang J, Ma X, Li T, Kong Z, Wang BL. A verticillium dahliae extracellular cutinase modulates plant immune responses. Mol Plant-Microbe Interact. 2017;31 (2):260-73.

35. Castellmiller CV, Gutierrezgonzalez JJ, Tu ZJ, Bushley KE, Hainaut M, Henrissat B, Samac DA. Genome assembly of the fungus Cochliobolus miyabeanus, and transcriptome analysis during early stages of infection on American Wildrice (Zizania palustris L.). Plos One. 2016;11(6):e0154122.

36. Gouran H, Gillespie H, Nascimento R, Chakraborty S, Zaini PA, Jacobson A, Phinney BS, Dolan D, Durbinjohnson BP, Antonova ES. The secreted protease PrtA controls cell growth, biofilm formation and pathogenicity in Xylella fastidiosa. Sci Rep. 2016;6:31098.

37. Gaillardin C: Lipases as pathogenicity factors of fungi. In: Timmis KN, editors. Handbook of hydrocarbon and lipid microbiology. Springer, Berlin, Heidelberg; 2010. p. 3259-3268.

38. Coetzer THT, Goldring JPD, LEJ H. Oligopeptidase B: A processing peptidase involved in pathogenesis. Biochimie. 2008:90(2):336-44.

39. Bourne Y, Henrissat B. Glycoside hydrolases and glycosyltransferases: families and functional modules. Curr Opin Struc Biol. 2001;11(5):593-600.

40. Zheng P, Xia YL, Xiao GH, Xiong CH, Hu X, Zhang SW, Zheng HJ, Huang Y, Zhou $Y$, Wang SY, et al. Genome sequence of the insect pathogenic fungus Cordyceps militaris, a valued traditional Chinese medicine. Genome Biol. 2011;12(11):R116.

41. Dimroth P. Primary sodium ion translocating enzymes. Biochim Biophysica Acta. 1997;1318(1-2):11-51.

42. Paulsen IT, Brown MH, Skurray RA. Proton-dependent multidrug efflux systems. Microbiol Rev. 1996;60(4):575-608.

43. de Waard MA. Significance of $A B C$ transporters in fungicide sensitivity and resistance. Pestic Sci. 1997;51(3):271-5.

44. Roohparvar R, De Waard MA, Kema GH, Zwiers LH. MgMfs1, a major facilitator superfamily transporter from the fungal wheat pathogen Mycosphaerella graminicola, is a strong protectant against natural toxic compounds and fungicides. Fungal Genet Biol. 2007;44(5):378-88.

45. Durairaj P, Hur JS, Yun $\mathrm{H}$. Versatile biocatalysis of fungal cytochrome P450 monooxygenases. Microb Cell Factories. 2016;15(1):1-16.

46. Kimura M, Tokai T, Takahashi-Ando N, Ohsato S, Fujimura M. Molecular and genetic studies of fusarium trichothecene biosynthesis: pathways, genes, and evolution. Biosci Biotechnol Biochem. 2007;71(9):2105-23. 
47. Butchko RA, Plattner RD, Proctor RH. Deletion analysis of FUM genes involved in tricarballylic ester formation during fumonisin biosynthesis. Agric Food Chem. 2006;54(25):9398-404.

48. Bojja RS, Cerny RL, Proctor RH, Du LC. Determining the biosynthetic sequence in the early steps of the fumonisin pathway by use of three gene-disruption mutants of Fusarium verticillioides. J Agr Food Chem. 2004; 52(10):2855-60.

49. Gao JX, Chen J. Transcriptome analysis identifies candidate genes associated with melanin and toxin biosynthesis and pathogenicity of the maize pathogen, Curvularia lunata. J Phytopathol. 2018;166(4):233-41.

50. Rep M, Van der Does HC, Meijer M, Van Wijk R, Houterman PM, Dekker HL, De Koster CG, Cornelissen BJC. A small, cysteine-rich protein secreted by Fusarium oxysporum during colonization of xylem vessels is required for 1-3mediated resistance in tomato. Mol Microbiol. 2010;53(5):1373-83.

51. Sornkom W, Miki S, Takeuchi S, Abe A, Asano K, Sone T. Fluorescent reporter analysis revealed the timing and localization of AVR-Pia expression, an avirulence effector of Magnaporthe oryzae. Mol Plant Pathol. 2017;18(8):1138.

52. Zheng X, Wagener N, Mclellan H, Boevink PC, Hua C, Birch PRJ, Brunner F. Phytophthora infestans RXLR effector SFI5 requires association with calmodulin for PTI/MTI suppressing activity. New Phytol. 2018;219(4):143346.

53. Medina CA, Reyes PA, Trujillo CA, Gonzalez JL, Bejarano DA, Montenegro NA, Jacobs JM, Joe A, Restrepo S, Alfano JR. The role of type III effectors from Xanthomonas axonopodis pv. Manihotis in virulence and suppression of plant immunity. Mol Plant Pathol. 2018;19(3):593-606.

54. Talbot NJ, Kershaw MJ, Wakley GE, De Vries O, Wessels J, Hamer JE. MPG1 encodes a fungal hydrophobin involved in surface interactions during infection-related development of Magnaporthe grisea. Plant Cell. 1996;8(6): 985.

55. Casarrubia S, Daghino S, Kohler A, Morin E, Khouja HR, Daguerre Y, Veneaultfourrey C, Martin FM, Perotto S, Martino E. The hydrophobin-like OmSSP1 may be an effector in the ericoid mycorrhizal symbiosis. Front Plant Sci. 2018;9:546.

56. Frías M, Brito N, González C. The Botrytis cinerea cerato-platanin BcSpl1 is a potent inducer of systemic acquired resistance (SAR) in tobacco and generates a wave of salicylic acid expanding from the site of application. Mol Plant Pathol. 2013;14(2):191-6.

57. Mentlak TA, Kombrink A, Shinya T, Ryder LS, Otomo I, Saitoh H, Terauchi R, Nishizawa Y, Shibuya N, Thomma BP, et al. Effector-mediated suppression of chitin-triggered immunity by Magnaporthe oryzae is necessary for rice blast disease. Plant Cell. 2012;24(1):322-35.

58. de Jonge R, van Esse HP, Kombrink A, Shinya T, Desaki Y, Bours R, van der Krol S, Shibuya N, Joosten MH, Thomma BP. Conserved fungal LysM effector Ecp6 prevents chitin-triggered immunity in plants. Science. 2010;329(5994): 953-5.

59. Kulkarni RD, Kelkar HS, Dean RA. An eight-cysteine-containing CFEM domain unique to a group of fungal membrane proteins. Trends Biochem Sci. 2003; 28(3):118-21.

60. Zhang ZN, Wu QY, Zhang GZ, Zhu YY, Murphy RW, Liu Z, Zou CG. Systematic analyses reveal uniqueness and origin of the CFEM domain in fungi. Sci Rep-UK. 2015;5:13032

61. Schafer W. Molecular mechanisms of fungal pathogenicity to plants. Annu Rev Phytopathol. 1994;32(1):461-77.

62. Moir A. How do spores germinate? J Appl Microbiol. 2006;101(3):526-30

63. Osherov N, May G. Conidial germination in Aspergillus nidulans requires RAS signaling and protein synthesis. Genetics. 2000;155(2):647-56.

64. Van Leeuwen MR, Van Doorn TM, Golovina EA, Stark J, Dijksterhuis J. Waterand air-distributed conidia differ in sterol content and cytoplasmic microviscosity. Appl Environ Microbiol. 2010;76(1):366-9.

65. Taheri-Talesh N, Horio T, Araujo-Bazan L, Dou X, Espeso EA, Penalva MA, Osmani SA, Oakley BR. The tip growth apparatus of Aspergillus nidulans. Mol Biol Cell. 2008:19(4):1439-49.

66. Leeuwen MRV, Smant W, Boer WD, Dijksterhuis J. Filipin is a reliable in situ marker of ergosterol in the plasma membrane of germinating conidia (spores) of Penicillium discolor and stains intensively at the site of germ tube formation. J Microbiol Meth. 2008;74(2):64-73.

67. Mares JH, Gramacho KP, Santos EC, da Silva SA, Santana JO, de Sousa AO, Alvim FC, Pirovani CP. Proteomic analysis during of spore germination of Moniliophthora perniciosa, the causal agent of witches' broom disease in cacao. BMC Microbiol. 2017:17(1):176.
68. Bassi D, Colla F, Gazzola S, Puglisi E, Delledonne M, Cocconcelli PS. Transcriptome analysis of Bacillus thuringiensis spore life, germination and cell outgrowth in a vegetable-based food model. Food Microbiol. 2016;55: $73-85$.

69. Schubert M, Lindgreen S, Orlando L. AdapterRemoval v2: rapid adapter trimming, identification, and read merging. BMC Res Notes. 2016;9(1):88.

70. Luo RB, Liu BH, Xie YL, Li ZY, Huang WH, Yuan JY, He GZ, Chen YX, Pan Q, Liu YJ. SOAPdenovo2: an empirically improved memory-efficient shortreadde novoassembler. GigaSci 2012; 1(1):18-18.

71. Bankevich A, Nurk S, Antipov D, Gurevich AA, Dvorkin M, Kulikov AS, Lesin VM, Nikolenko SI, Pham S, Prjibelski AD. SPAdes: a new genome assembly algorithm and its applications to single-cell sequencing. J Comput Biol. 2012:19(5):455-77.

72. Stanke M, Tzvetkova A, Morgenstern B. AUGUSTUS at EGASP: using EST, protein and genomic alignments for improved gene prediction in the human genome. Genome Biol. 2006; 7 Suppl 1:S11 11-18.

73. Nielsen $\mathrm{H}$, Engelbrecht J, Brunak S, von Heijne G. Identification of prokaryotic and eukaryotic signal peptides and prediction of their cleavage sites. Protein Eng. 1997;10(1):1-6.

74. Petersen TN, Brunak S, von Heijne G, Nielsen H. SignalP 4.0: discriminating signal peptides from transmembrane regions. Nat Methods. 2011;8(10):7856.

75. Chen Y, Yu P, Luo J, Jiang Y. Secreted protein prediction system combining CJ-SPHMM, TMHMM, and PSORT. Mamm Genome. 2003;14(12):859-65.

76. Eisenhaber B, Bork P, Eisenhaber F. Sequence properties of GPI-anchored proteins near the omega-site: constraints for the polypeptide binding site of the putative transamidase. Protein Eng. 1998;11(12):1155-61.

77. Graham MA, Silverstein KAT, Cannon SB, VandenBosch KA. Computational identification and characterization of novel genes from legumes. Plant Physiol. 2004;135(3):1179-97.

78. Rawlings ND, Barrett AJ, Thomas PD, Huang X, Bateman A, Finn RD. The MEROPS database of proteolytic enzymes, their substrates and inhibitors in 2017 and a comparison with peptidases in the PANTHER database. Nucleic Acids Res. 2018;46(D1):D624-32.

79. Saier MH, Tran CV, Barabote R. TCDB: the transporter classification database for membrane transport protein analyses and information. Nucleic Acids Res. 2006:34(Database issue):181-6.

80. Schomburg D, Schomburg I. Enzyme databases. Methods Mol Biol. 2010; 609:113-28

81. Khaldi N, Seifuddin FT, Turner G, Haft D, Nierman WC, Wolfe KH, Fedorova ND. SMURF: genomic mapping of fungal secondary metabolite clusters. Fungal Genet Biol. 2010;47(9):736-41.

82. Larkin MA, Blackshields G, Brown NP, Chenna R, McGettigan PA, McWilliam $H$, Valentin F, Wallace IM, Wilm A, Lopez R, et al. Clustal W and Clustal X version 2.0. Bioinformatics. 2007;23(21):2947-8.

83. Andrews S. Babraham Bioinformatics: FastQC A Quality Control tool for High Throughput Sequence Data. In.; 2010

84. Langmead B, Salzberg SL. Fast gapped-read alignment with bowtie 2. Nat Methods. 2012;9(4):357-9.

85. Love Ml, Huber W, Anders S. Moderated estimation of fold change and dispersion for RNA-seq data with DESeq2. Genome Biol. 2014;15(12):550.

86. Pfaffl MW. A new mathematical model for relative quantification in real-time RT-PCR. Nucleic Acids Res. 2001;29(9):e45.

\section{Publisher's Note}

Springer Nature remains neutral with regard to jurisdictional claims in published maps and institutional affiliations.

\section{Ready to submit your research? Choose BMC and benefit from:}

- fast, convenient online submission

- thorough peer review by experienced researchers in your field

- rapid publication on acceptance

- support for research data, including large and complex data types

- gold Open Access which fosters wider collaboration and increased citations

- maximum visibility for your research: over $100 \mathrm{M}$ website views per year

At $\mathrm{BMC}$, research is always in progress.

Learn more biomedcentral.com/submissions 